\title{
Lateral-distortional buckling of continuous steel-concrete composite beam
}

\section{Flambagem lateral com distorção de vigas mistas de aço e concreto contínuas}

T. V. AMARAL a thaisvervloetamaral@gmail.com

J.P. S. OLIVEIRA b janainapenas@gmail.com

A. F. G. CALENZANI afcalenzani@gmail.com

F.B. TEIXEIRA b

felipebarbosateixeira@gmail.com

\begin{abstract}
In hogging bending moment regions of continuous composite beams the collapse by lateral-distortional buckling (LDB) can occur. The design against LDB according to ABNT NBR 8800:2008 begins with the determination of the elastic critical moment, which depends, among other factors, of the distribution of the bending moment in the analyzed span, taken into account in the formulation through the modification parameter $\mathrm{C}_{\text {dis }}$. To assess the analytical formulations prescribed by ABNT NBR 8800:2008, numerical FE models that simulate the LDB behavior of continuous steelconcrete composite beams were developed in this paper. The different boundary conditions presented in ABNT NBR 8800:2008 were checked using two different models: a simplified model, with a single simply supported span; and models with multiple internal supports and more than one span. It was observed that the $C_{\text {dist }}$ values prescribed by ABNT NBR 8800:2008 can be unsafe, and therefore new values for $C_{\text {dist }}$ are proposed in this paper.
\end{abstract}

Keywords: elastic critical moment, lateral-distortional buckling, continuous composite beams.

\section{Resumo}

Nas regiões de momento negativo de vigas mistas contínuas pode ocorrer a flambagem lateral com distorção (FLD). A verificação à FLD pela ABNT NBR 8800:2008 tem como procedimento inicial determinar o momento crítico elástico que depende, dentre outros fatores, da distribuição do momento fletor no vão analisado, considerada por meio do parâmetro de modificação $C_{\text {dist }}$. Para avaliar a formulação analítica prescrita pela norma ABNT NBR 8800:2008, nesse trabalho, modelos numéricos em elementos finitos, que representam o comportamento à FLD de vigas mistas foram desenvolvidos. As diferentes condições de contorno apresentadas na ABNT NBR 8800:2008 foram verificadas, considerando duas modelagens distintas: modelo simplificado com um vão biapoiado e modelos com mais de um vão. Foi notado que os valores de $\mathrm{C}_{\text {dist }}$ da $\mathrm{ABNT}$ NBR 8800:2008 podem conduzir a resultados contrários à segurança, por isso, propõem-se, neste trabalho, novos valores para $\mathrm{C}_{\text {dist: }}$

Palavras-chave: momento crítico elástico, flambagem lateral com distorção, vigas mistas contínuas. 


\section{Introduction}

The main advantage of the use of continuous steel-concrete composite beams is the redistribution of the bending moment along the member's length, which allows for the use of smaller steel cross-sections and increases the overall structural stiffness. However, continuous composite beams are subjected to hogging bending moments at the internal supports, making them susceptible to lateral-distortional buckling (LDB).

In the hogging moment region of continuous composite beams the bottom flange is under compression, giving it the propensity to buckle about its major second moment of area axis since buckling about the minor second moment of area axis is prevented by the web. The top flange is connected through shear connectors to the concrete slab, which prevents the steel cross-section from rotating in-plane as a whole. If the web of the steel section does not have enough stiffness to prevent lateral bending it will distort, characterizing the failure mode named lateral-distortional buckling (LDB), shown in Figure 1.

To determine the composite beam's LDB strength the Brazilian standard ABNT NBR 8800:2008 provides an approximated method similar to that found in the European standard EN 19941-1:2004, which first determines the elastic critical moment, $M_{c r}$ to then calculate the ultimate design strength. Equation 1 is the one prescribed by ABNT NBR 8800:2008 for the determination of $M_{c r}$ and was obtained by Roik, Hanswille and Kina [8] by applying the energy method.

$M_{c r}=\frac{C_{d i s t} \alpha_{g}}{L} \sqrt{\left(G_{a} J+k_{r} \frac{L^{2}}{\pi^{2}}\right) E_{a} I_{\text {afy }}}$

in which $G$ is the steel transverse elastic modulus; $L$ is the length of the beam between vertical supports (both flanges must be laterally contained at these supports); $\mathrm{J}$ is the torsional constant of the steel section; $I_{\text {afy }}$ is the second moment of area of the bottom flange about its y axis (Figure 1); Cdist is a coefficient that depends upon the bending moment distribution along the member length $L ; k_{r}$ is the rotational stiffness of the composite beam; $\alpha_{g}$ is a factor associated with the geometry of the crosssection of the composite beam.

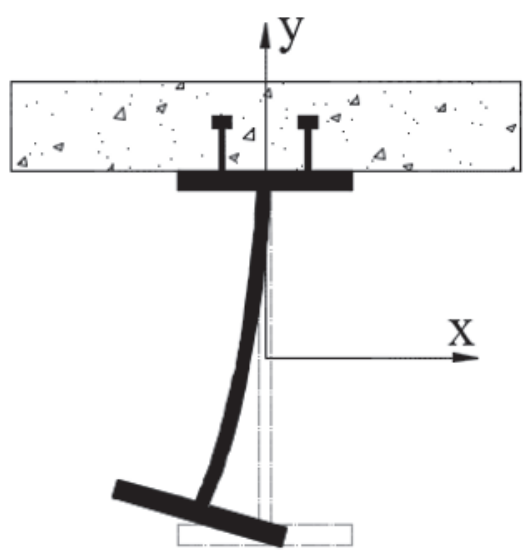

Figure 1

Lateral-distortional buckling
For doubly symmetric sections the $\alpha_{g}$ factor is determined by the following expression:

$$
\alpha_{g}=\frac{\left(\frac{h_{0} I_{x}}{I_{a x}}\right)}{\frac{\left(\frac{h_{0}^{2}}{4}+\frac{\left(I_{a x}+I_{a y}\right)}{A_{a}}\right)}{e}+h_{0}}
$$

in which:

$$
e=\frac{A I_{a x}}{A_{a} y_{c}\left(A-A_{a}\right)}
$$

and $y_{r}$ is the distance from the geometric center of the steel section to the midplane of the concrete slab; $I_{x}$ is the second moment of area of the composite section at the hogging moment region (taking into account the steel section and the steel reinforcement of the concrete slab) about the $x$ axis; $I_{a x}$ and $I_{a y}$ are the second moments of area of the steel section about its $x$ and $y$ axes, respectively; $A_{a}$ is the area of the steel section; $A$ is the area of the composite section at the hogging moment region (taking into account the steel section and the steel reinforcement of the concrete slab); $b_{0}$ is the distance between the geometric centers of the top and bottom flanges of the steel section.

In order to obtain the elastic critical moment equation (Equation 1) the structural behavior associated with the LDB was simulated using an inverted "U" mechanism, composed of two adjacent beams and a concrete slab to which the steel beams are connected (Figure 2-a). In Figure 2-b the simplified model adopted by Roik, Hanswille and Kina [8], consisting of a composite beam of length $L$ subjected to bending moments of opposite signs at both ends, is presented. In this simplified model the rotational stiffness of the composite beam $\left(\mathrm{k}_{\mathrm{r}}\right)$ is replaced by introducing a spring connected to the top flange of the steel section. The spring acts as a surrogate for the composite action of the " $U$ " mechanism in the determination of the ultimate LDB strength, replacing the combined stiffness associated with the bending of the concrete slab, the distortion of the web and the deformation of the shear connection.

From Figure 2 it is possible to notice that the simplified model (Figure 2-b) must include an axial force $\mathrm{N}_{\mathrm{a}}$ so that in it the position of the elastic neutral axis coincides with its position in the composite beam being represented (Figure 2-a). In addition, the elastic critical moment of the composite beam $M_{c r}$ (Figure 2-a) is determined based on the elastic critical moment of the steel section $M_{a}$ (Figure 2-b) using the following relation:

$M_{c r}=\mathrm{M}_{\mathrm{a}} \frac{I_{x}}{I_{a x}}$

the axial force in the steel section is given by:

$N_{a}=\frac{\mathrm{M}_{\mathrm{a}}}{I_{a x}} \bar{y} A_{a}$

in which $\bar{y}$ is the distance between the neutral axes of the steel section and of the composite section. The rotational stiffness of the inverted " $U$ " mechanism is fundamental for the calculation of the elastic critical moment. This stiffness $k_{0}$ is calculated as the stiffness of a sequence of three springs connected in series that represent the stiffnesses of the concrete slab $\left(k_{1}\right)$, of the steel section web $\left(\mathrm{k}_{2}\right)$, and of the shear connection $\left(\mathrm{k}_{3}\right)$. For steel sections with a plane web the stiffness $k_{3}$ displays a much higher value than the other two stiffnesses, being therefore eliminated from the calculation to determine the value of the overall stiffness 
$\mathrm{k}_{\mathrm{r}}$. Consequently, the rotational stiffness $\mathrm{k}_{\mathrm{r}}$ for steel sections with a flat web is given by the following expression:

$k_{r}=\frac{\mathrm{k}_{1} k_{2}}{k_{1}+k_{2}}$

in which,

$k_{1}=\frac{\alpha(E I)_{2}}{a}$

and

$k_{2}=\frac{\mathrm{Et}_{\mathrm{w}}^{3}}{4 h_{0}\left(1-v_{a}^{2}\right)}$

in which $\alpha$ is a coefficient that has its value dependent upon the position of the steel section: if the section is situated at the edges of the slab $\alpha$ is equal to 2 , and if the section is placed in the inner region of the slab $\alpha$ is equal to 3 (for internal sections with four or more similar neighboring sections $\alpha$ can be taken as 4$) ;(E I)_{2}$ is the bending stiffness of the homogenized composite section (disregarding concrete under tension) by unit length of the beam, taken as the smallest value among the stiffnesses at the center of the span and at the internal support; $a$ is the distance between parallel beams (Figure 2-a); $E$ is the elastic modulus of the steel section; $t_{w}$ is the thickness of the steel section's web (Figure 2-a); $h_{0}$ is the distance between the geometric centers of the steel section's top and bottom flanges (Figure 2-b); $v_{a}$ is the steel's Poisson coefficient. In Equation 1 it can be noted that the elastic critical moment is

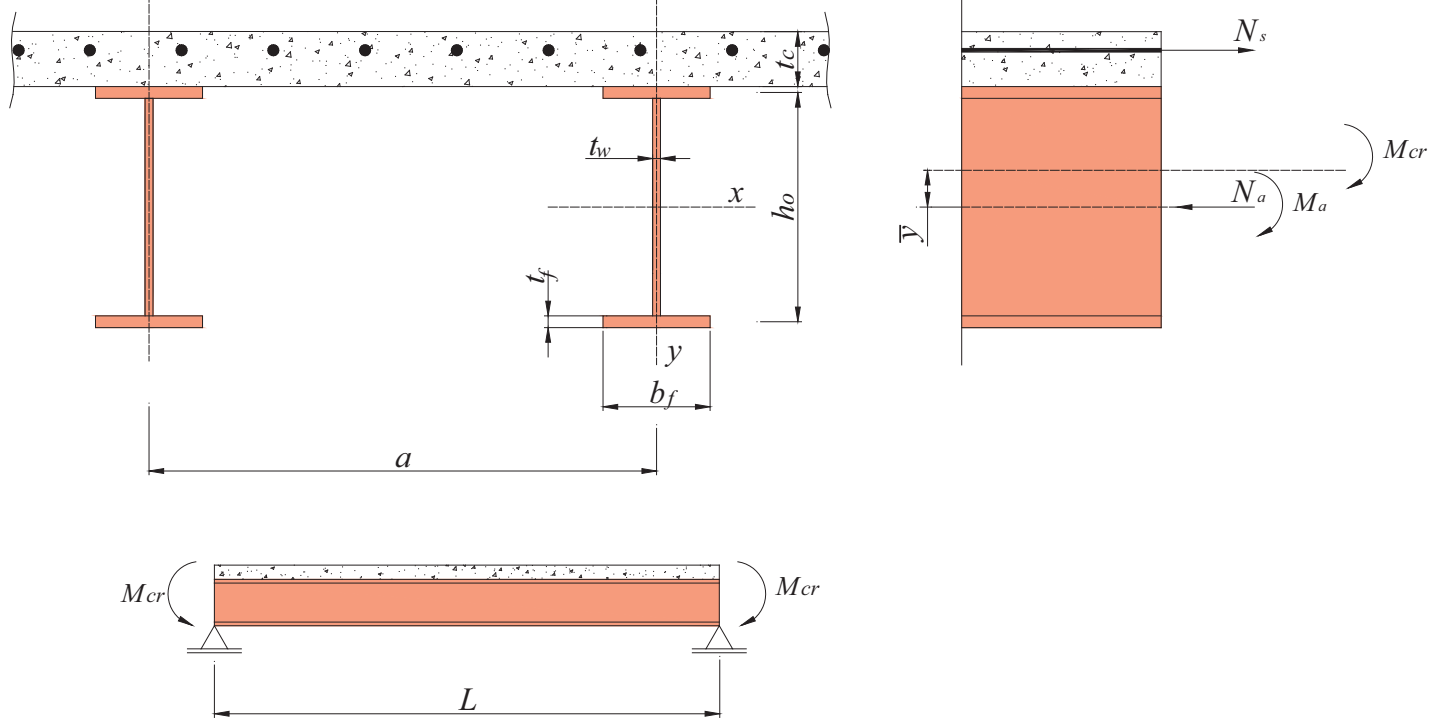

a) "U" mechanism
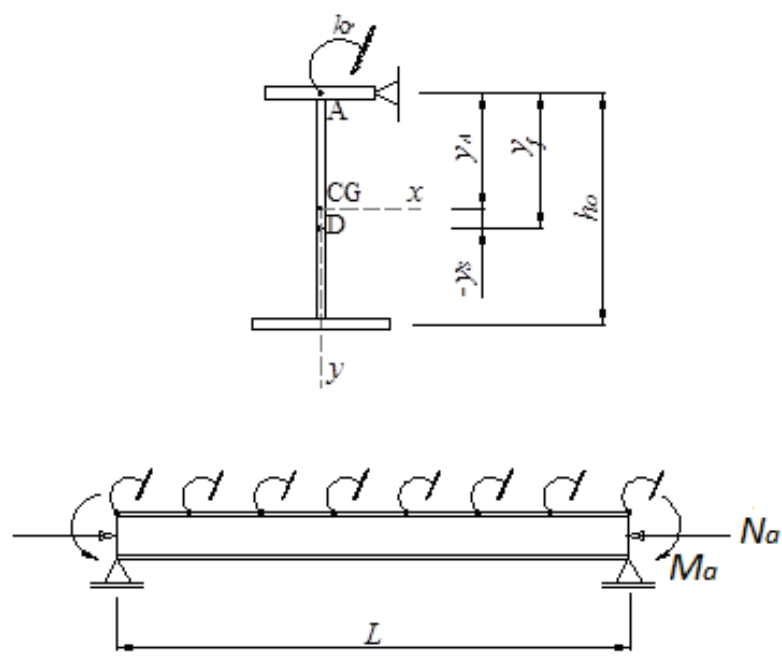

b) Simplified model by Roik, Hanswille and Kina [8]

\section{Figure 2}

Models for the determination of the elastic critical moment 
influenced by the shape of the bending moment diagram along the length of the beam, an effect that is captured by the coefficient $\mathrm{C}_{\text {dist. }}$. The values of this coefficient for continuous plain-webbed composite beams were determined by means of numerical analyses employing finite element simulations and are presented as tabled values by ABNT NBR 8800:2008. Table 1 and Table 2 list the values of $C_{\text {dist }}$ for spans with uniformly distributed transverse loads, spans with point loads, and spans without loading along the length $L$.

Recent studies were performed to evaluate the elastic critical moment associated with LDB of continuous composite beams. Chen and Wang [4] analyzed numerically the structural behavior of continuous composite beams with and without transverse webstiffeners welded to the steel section. The beams were simulated using the finite element analysis software Ansys in order to study their behavior in the hogging moment region. The following parameters, which might affect the resistant capacity of the composite beam, were analyzed: bending stiffness of the concrete slab, stiffness of the stiffened web, slenderness of the steel section web, and the ratio of the distance between web stiffeners to the length of the beam. Chen and Wang [4] performed linear buckling and non-linear analyses. For the linear buckling analyses the model consisted of a simply supported steel beam subjected to hogging moment and with rotational restriction and lateral bracing applied to the top flange. The rotational restriction was imposed by using a torsional spring with a stiffness $\mathrm{k}_{\mathrm{r}}$ calculated using the formulation proposed by EN 1994-1-1:2004. In their parametric studies Chen and Wang [4] compared beams with identical crosssections with and without web stiffeners and concluded that such stiffeners increase the value of the elastic critical moment of composite beams and reduce the lateral displacement of the compressed flange.

Oliveira et al. [7] proposed a procedure to obtain the elastic critical moment associated with LDB of composite steel-concrete beams built with a sinusoidal web based on the results of numerical analyses simulating the inverted " $U$ " mechanism. The proposed procedure uses the Roik, Hanswille and Kina [8] equation considering the geometric properties of a steel section with a sinusoidal web.

\section{Table 1}

Values of $\mathrm{C}_{\text {dist }}$ for spans with uniformly distributed or point loads, adapted from ABNT NBR 8800:2008

\begin{tabular}{|c|c|c|c|c|c|c|c|c|c|c|}
\hline \multirow{2}{*}{$\begin{array}{l}\text { Loading } \\
\text { and } \\
\text { boundary } \\
\text { conditions }\end{array}$} & \multirow{2}{*}{$\begin{array}{l}\text { Bending } \\
\text { moment } \\
\text { diagram } 1\end{array}$} & \multicolumn{9}{|c|}{$C_{\text {dist }}$} \\
\hline & & $\psi=0.50$ & $\psi=0.75$ & $\psi=1.00$ & $\psi=1.25$ & $\psi=1.50$ & $\psi=1.75$ & $\psi=2.00$ & $\psi=2.25$ & $\psi=2.50$ \\
\hline \multirow{2}{*}{$C_{\psi}^{W+\cdots+n}$} & $\sum^{M_{0}}$ & 41.5 & 30.2 & 24.5 & 21.1 & 19.0 & 17.5 & 16.5 & 15.7 & 15.2 \\
\hline & $\psi \mathrm{M}_{0} \longrightarrow^{\mathrm{M}_{0}}$ & 33.9 & 22.7 & 17.3 & 14.1 & 13.0 & 12.0 & 11.4 & 10.9 & 10.6 \\
\hline \multirow{2}{*}{$\left(\varphi^{m+n+1)}\right)$} & $\prod_{1}^{M_{0} M_{0}} \overbrace{}^{0.75 \psi M_{0}}$ & 28.2 & 18.0 & 13.7 & 11.7 & 10.6 & 10.0 & 9.5 & 9.1 & 8.9 \\
\hline & ${ }^{\psi \mathrm{M}_{0}} \overbrace{}^{\psi \mathrm{M}_{\mathrm{o}}}$ & 21.9 & 13.9 & 11.0 & 9.6 & 8.8 & 8.3 & 8.0 & 7.8 & 7.6 \\
\hline$\frac{1}{(Y}$ & ${ }^{\psi \mathrm{M}_{\mathrm{o}}}$ & 28.4 & 21.8 & 18.6 & 16.7 & 15.6 & 14.8 & 14.2 & 13.8 & 13.5 \\
\hline$\left(\begin{array}{l}1 \\
(y+4)\end{array}\right.$ & $\psi \mathrm{M}_{\mathrm{o}} \triangle \sum^{\mathrm{M}_{\mathrm{o}}}{ }^{\psi \mathrm{M}_{\mathrm{o}}}$ & 12.7 & 9.89 & 8.6 & 8.0 & 7.7 & 7.4 & 7.2 & 7.1 & 7.0 \\
\hline
\end{tabular}

\section{Table 2}

Values of $\mathrm{C}_{\text {dist }}$ for spans without loading along the length L, adapted from ABNT NBR 8800:2008

\begin{tabular}{|c|c|c|c|c|c|c|}
\hline \multirow{2}{*}{$\begin{array}{l}\text { Loading and } \\
\text { boundary } \\
\text { conditions }\end{array}$} & \multirow{2}{*}{$\begin{array}{l}\text { Bending moment } \\
\text { diagram }{ }^{1}\end{array}$} & \multicolumn{5}{|c|}{$\mathbf{C}_{\text {dist }}$} \\
\hline & & $\psi=0.00$ & $\psi=0.25$ & $\psi=0.50$ & $\psi=0.75$ & $\psi=1.00$ \\
\hline$\left(\begin{array}{ll}( & \psi\end{array}\right)$ & $\mathrm{M} \underset{\text { acceptable }}{ } \cup \mathrm{M}$ & 11.1 & 9.5 & 8.2 & 7.1 & 6.2 \\
\hline$\left(\begin{array}{ll}Y & Y\end{array}\right)$ & ${ }_{\text {acceptable }}^{\mathrm{M}} \mathrm{M}_{\mathrm{M}}$ & 11.1 & 12.8 & 14.6 & 16.3 & 18.1 \\
\hline
\end{tabular}

Note: ' $\mathrm{M}$ is the maximum design hogging moment, in absolute value, at the analyzed span, considering that $\psi$ values grater than 1.00 have to be taken as 1.00 . 
In addition to that, Oliveira et al. [7] recommend adopting, in the calculation of the rotational stiffness, the formulation proposed by Calenzani et al. [2]. New values for the $C_{\text {dist }}$ coefficient were proposed by Oliveira et al. [7] for continuous composite beams with sinusoidal webs either subjected to uniformly distributed transverse load or without loading along their length. The values of the elastic critical moment calculated using the procedure proposed by Oliveira et al. [7] displayed good agreement with the values obtained through numerical analysis using the finite element software Ansys.

In this work, numerical models were created using ANSYS 15.0 [1] to simulate the lateral-distortional buckling behavior of composite steel-concrete beams in order to analyze the influence of the $C_{\text {dist }}$ coefficient in the value of the elastic critical moment. The numerical model was validated using the numerical results of Chen and Wang [4]. To analyze the analytical formulation for $M_{c r}$ prescribed by ABNT NBR 8800:2008 the composite beams were simulated with different boundary conditions, resulting in one hundred and eighteen different numerical models.

\section{Validation of the numerical model}

The finite element software ANSYS 15.0 [1] was used to create the numerical models with which the critical buckling load was calculated by performing a linear buckling analysis. The finite element model created to calculate the elastic critical moment associated with LDB is described in item 2.1. In order to determine which boundary conditions are ideal to simulate this physical problem a preliminary study of different forms of applying loads and creating supports was performed and is described in item 2.2. The validation of the numerical model was done by comparing the numerical results obtained in this paper against the numerical results published by Chen and Wang [4].

\subsection{Description of the numerical model}

In the numerical model of the steel-concrete composite beam used in this work neither the concrete slab nor the shear connectors were modeled. To simulate the inverted "U" mechanism a torsional

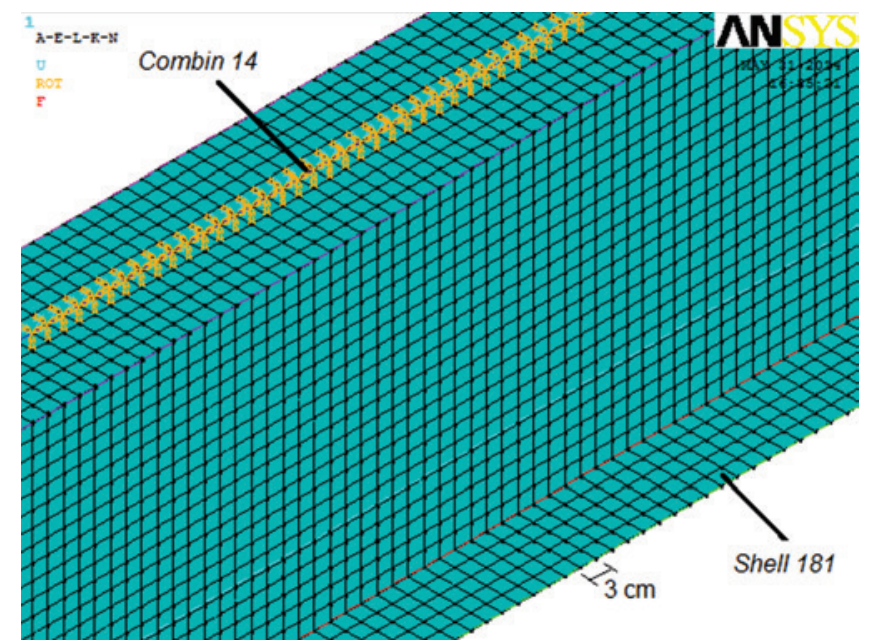

Figure 3

Finite element mesh adopted by Oliveira [6]

spring (with stiffness $\mathrm{k}_{\mathrm{r}}$ ) and continuous lateral bracing were applied to the centerline of the top flange along the whole length of the beam. The numerical model is similar to the one adopted by Oliveira [6], composed of SHELL181 elements simulating the steel section and COMBIN14 elements simulating the torsional springs (Figure 3). The torsional stiffness $k_{r}$ was taken as the value of the concrete slab's flexural stiffness $\left(k_{1}\right)$, obtained from Equation 7 , since the steel web's stiffness $\left(k_{2}\right)$ is already accounted for in the numerical model by the presence of the SHELL181 elements that make up the steel profile's web.

The finite element mesh was created using Ansys's mapped meshing option, which is capable of generating rectangular $2 \mathrm{D}$ elements in a regular pattern. The size of the shell elements was chosen to be $3 \mathrm{~cm}$ based on the mesh refinement studies performed by Oliveira [6].

The results obtained and presented by Chen and Wang [4] were used to validate the numerical model. The finite element model adopted by Chen and Wang [4] consists of a simply supported

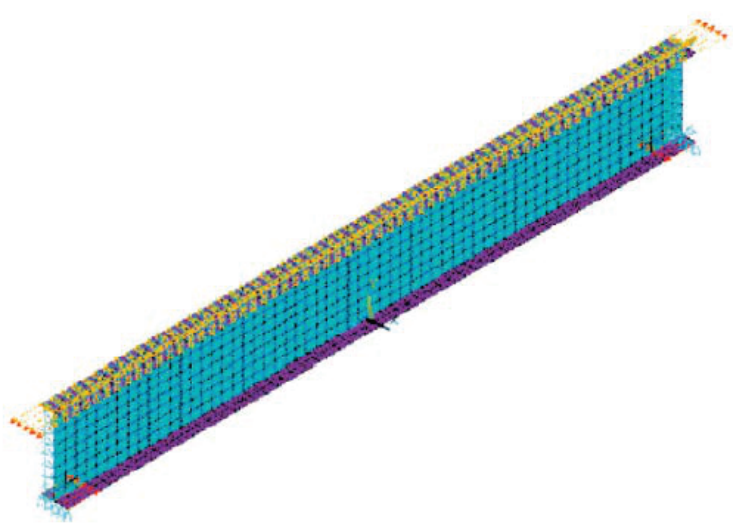

a) Numerical model

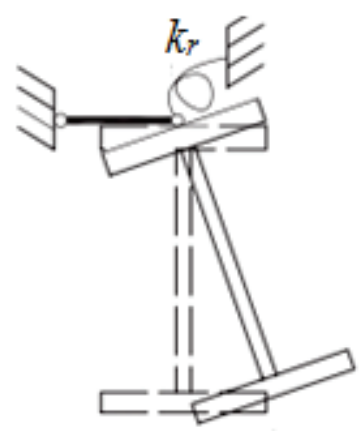

b) Rotational restriction

Figure 4

Numerical model by Chen and Wang [4] 


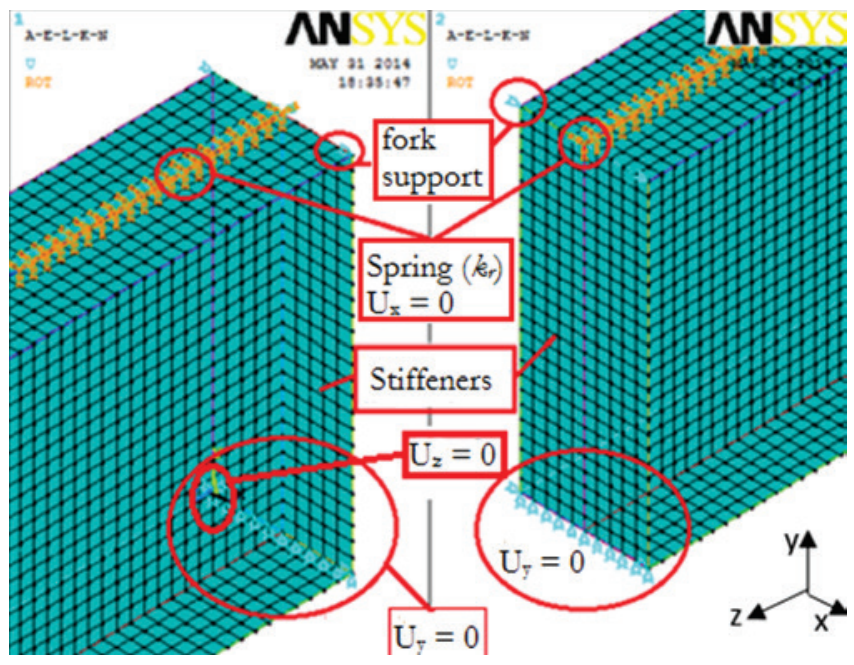

Figure 5

Boundary conditions of model MT-1

welded steel beam, subjected to a hogging bending moment $M_{a}$ of constant value along its length and with rotational restriction and lateral bracing applied to the top flange (Figure 4-a). In order to simplify the model the axial force $\mathrm{N}_{\mathrm{a}}$ was not applied to the steel section. The rotational restriction at the top flange was applied by using springs, as presented in Figure 4-a. The numerical model created by Chen and Wang [4] was validated by comparing their results against those obtained by $\mathrm{Ng}$ and Ronagh [5], who performed numerical analyses of composite I beams.

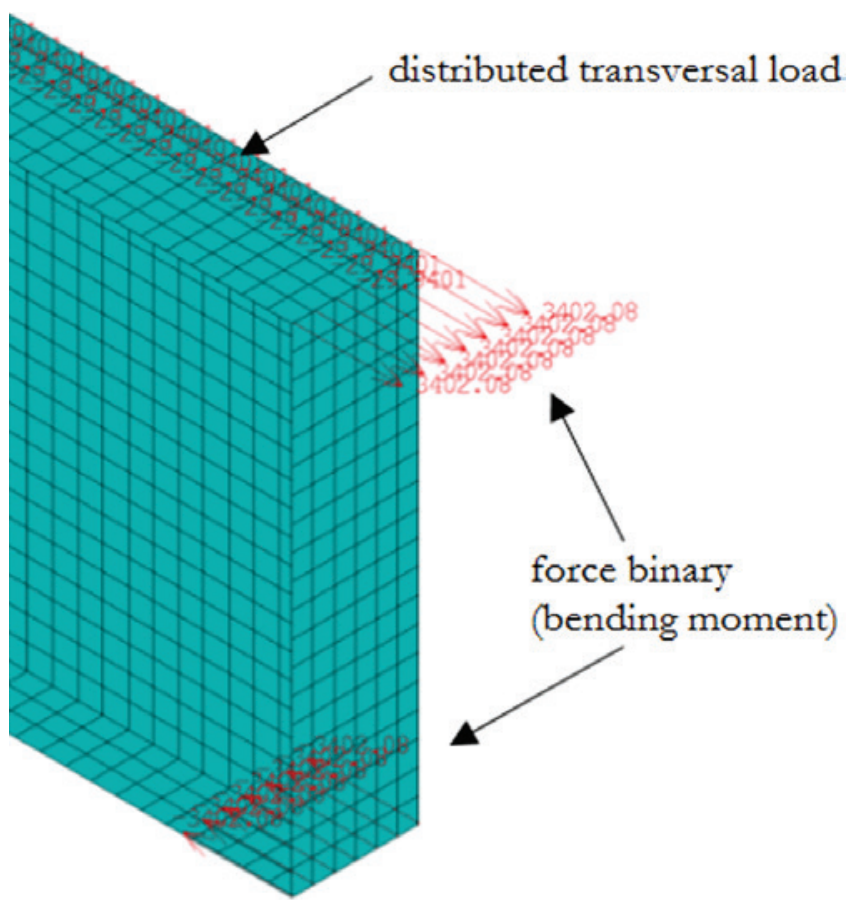

Figure 6

Loads applied in model MT-1
In their parametric study, Chen and Wang [4] used a steel section with an $800 \mathrm{~mm}$ depth (d), a $320 \mathrm{~mm}$ flange width $\left(b_{f}\right)$, a $16 \mathrm{~mm}$ flange thickness $\left(t_{f}\right)$, and a $10 \mathrm{~mm}$ web thickness $\left(t_{w}\right)$. Different ratios between the span ( $L$ ) and the section depth (d) were analyzed by Chen and Wang [4].

To validate the numerical model used in this work, simply supported beams with the same geometric characteristics of those studied by Chen and Wang [4] were modeled, with span-depth ratios (L/d) of either 8 or 12. The steel's Poisson's coefficient and elastic modulus were taken as 0.3 and $200 \mathrm{GPa}$, respectively.

\subsection{Boundary condition study}

To determine the most adequate manner to apply the boundary conditions different situations (identified as MT-1 through MT-10) were simulated in numerical models with a single simply supported span.

In the first model, MT-1 (Figure 5), web stiffeners were added at the extremities of the beam, a common situation in real life structures since such stiffeners are often used to create connections for composite beams. Vertical displacement was restricted $(U Y=0)$ in all the nodes of the bottom flange at both supports and longitudinal displacement was restricted $(\mathrm{UZ}=0)$ in a single node of the bottom flange of one of the supports. Lateral displacement was restricted $(U X=0)$ in the four corners of the top and bottom flanges at both supports. The bending moment was applied at one end by means of a force binary acting upon the top and bottom flanges, as illustrated in Figure 6. In addition, the distributed load was applied as a series of nodal forces in the $Y$ direction acting on the nodes placed at the intersection of the top flange and the web along the whole span of the beam.

Model MT-2 is identical to model MT-1 except for the web stiffeners, which have been removed. This model was created to explore the hypothesis that the web stiffeners imposed a warping restriction at the supports that made the behavior deviate from that of a fork support, the desired boundary condition.

To evaluate the influence of the position of the vertical support, in model MT-3 the restriction UY $=0$ was applied, at both supports, at a single node located in the centroid of the steel section (Figure 7). The longitudinal restriction $U Z=0$ was kept at the bottom flange of

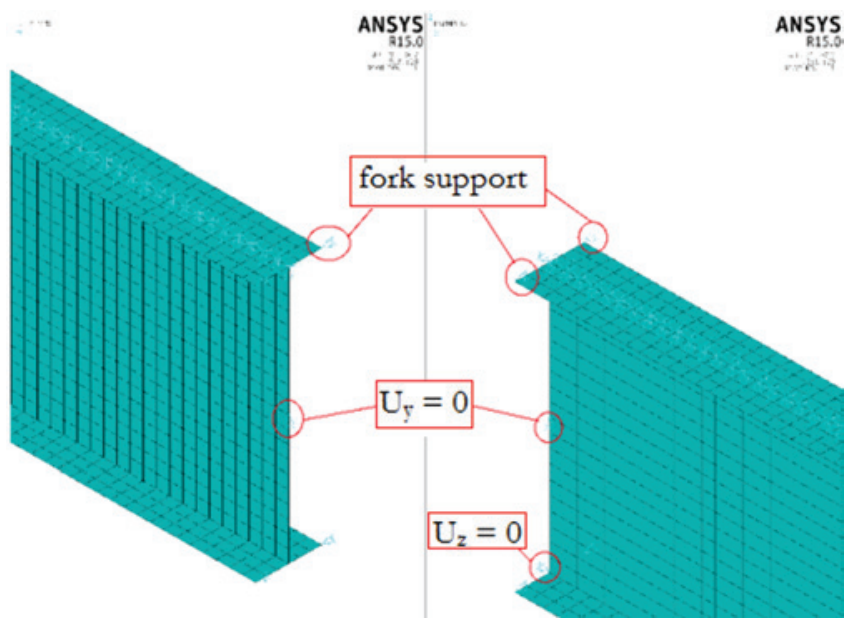

Figure 7

Boundary conditions in model MT-3 


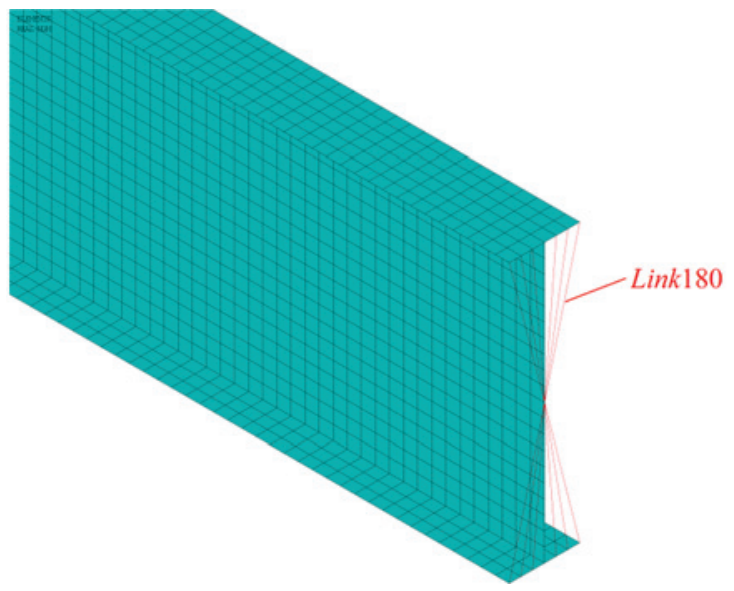

Figure 8

Boundary conditions in model MT-4

the steel section. In this model the web stiffeners were not included at the supports. The loads are applied as in MT-1, as illustrated in Figure 5.

The model MT-4 is identical to MT-3 in all aspects but one: in MT-4 additional truss elements (LINK180) were added at both supports connecting each node of the cross section to the node at the centroid of the steel section (Figure 8). The purpose of this stiffening is to reduce or eliminate distortion of the steel section at the supports. The loads were applied as in MT-1 (Figure 6).

To evaluate the influence of the position of the longitudinal support ( $z$ direction) the model MT-5 was given the same boundary conditions as MT-4, with the exception that the position of the $\mathrm{UZ}=0$ restriction was moved from the node at the bottom of the steel section to the node at its centroid (Figure 9). The loads were applied as in MT-1 (Figure 6).

The approach adopted to apply the bending moment at the extremities was also studied. In model MT-6 (same boundary conditions as MT5) the magnitude of the axial nodal forces applied at the end of the beam varied linearly with the depth of the section (Figure 10). This

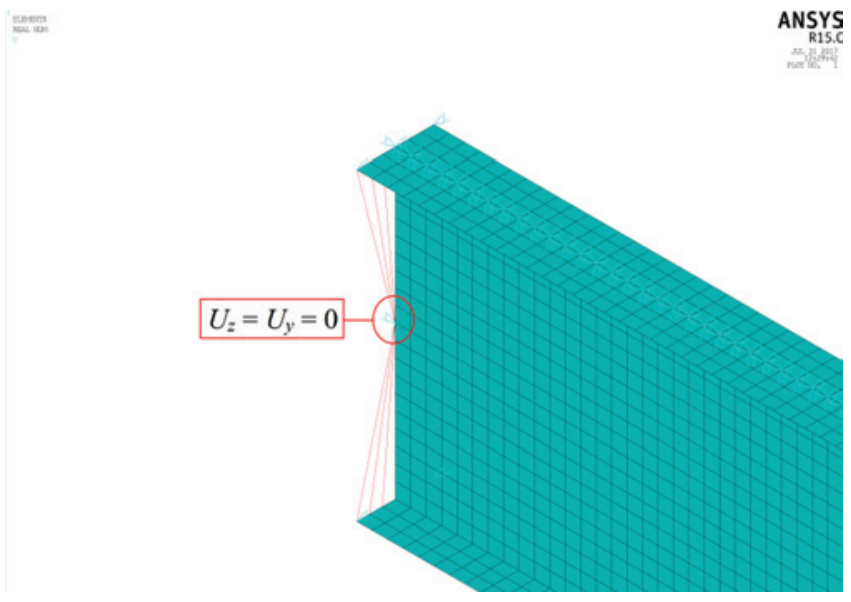

\section{Figure 9}

Boundary conditions in model MT-5 force distribution generates a stress pattern that matches the elastic stress diagram of beams undergoing bending. This triangular force distribution replaces the force binary at the flanges previously adopted to introduce the bending moment, but the uniformly distributed transversal loads were applied as described for MT-1.

Model MT-7 has the same boundary conditions as MT- 1 but the bending moment at the extremity was applied using the triangular force diagram described for MT-6 (Figure 10).

In models MT-1 through MT-7 the bending moment was applied at a single extremity. In order to simulate an internal span the model MT-8 was created with the same boundary conditions and load introduction approach as MT-1 (Figure 6), the only difference being that the bending moment was applied at both extremities. Model MT-9 has the same boundary condition configuration as MT-1, but the bending moment was applied at both extremities using the elastic triangular diagram described for MT-6 (Figure 10). Finally, model MT-10 is a copy of model MT- 6 with bending moment applied at both ends.

Table 3 compiles the characteristics of the numerical models MT-1 through MT-10 used in the study of boundary conditions performed in this paper. Table 4 displays the numerical results $\lambda_{\text {ANSYS }}$ (eigenvalues of the linear buckling analysis) along with the buckling mode observed (LWB stands for local web buckling). The reference values were taken from MT-1 for models with bending moment at a single end and from MT-8 for models with bending moment at both ends. The ratios between the eigenvalues of the reference model $\left(\lambda_{\text {REF }}\right)$ and the eigenvalues of each model $\left(\lambda_{\text {ANSYS }}\right)$ are also presented in Table 4.

From Table 4 the importance of the introduction of some form of restriction against distortion at the supports (either web stiffeners or LINK180 truss elements) becomes clear, since models without such restriction displayed the local phenomenon of web buckling instead of the global phenomenon of lateral-distortional buckling.

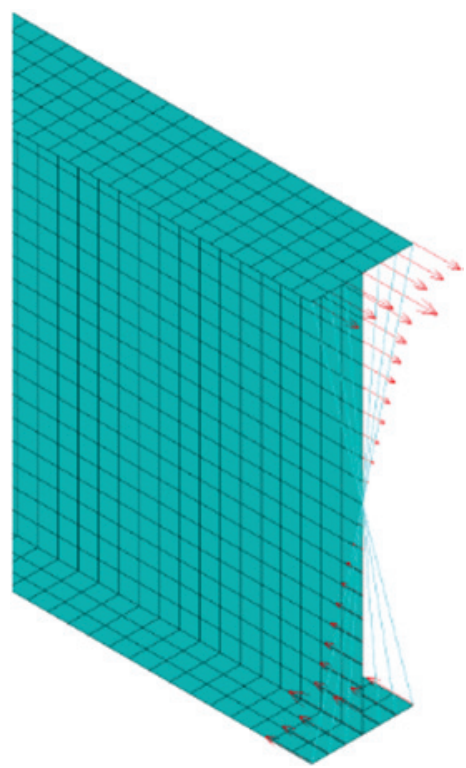

Figure 10

Bending moment applied at an extremity of the steel section in model MT-6 
Table 3

Boundary conditions studied

\begin{tabular}{|c|c|c|c|c|c|}
\hline Model & $\begin{array}{c}\text { Web stiffeners } \\
\text { at supports }\end{array}$ & $\begin{array}{c}\text { Distortional } \\
\text { restriction } \\
\text { (Link 180) }\end{array}$ & $\begin{array}{c}\text { Position of } \\
\text { vertical support }\end{array}$ & $\begin{array}{c}\text { Position of } \\
\text { longitudinal } \\
\text { support }\end{array}$ & $\begin{array}{c}\text { Bending moment } \\
\text { application }\end{array}$ \\
\hline MT-1 & Yes & No & Bottom flange & Bottom flange & Force binary \\
\hline MT-2 & No & No & Bottom flange & Bottom flange & Force binary \\
\hline MT-3 & No & No & Centroid & Bottom flange & Force binary \\
\hline MT-4 & No & Yes & Centroid & Bottom flange & Force binary \\
\hline MT-5 & No & Yes & Centroid & Centroid & Force binary \\
\hline MT-6 & No & Nos & Centroid & Centroid & Elastic diagram \\
\hline MT-7 & Yes & No & Bottom flange & Bottom flange & Force binary \\
MT-8 & Yes & No & Bottom flange & Bottom flange & Elastic diagram \\
MT-9 & No & Yes & Centroid & Centroid & Elastic diagram \\
\hline
\end{tabular}

Table 4

Results obtained

\begin{tabular}{|c|c|c|c|}
\hline Model & $\lambda_{\text {ANsYs }}$ & $\lambda_{\text {Reference }} / \lambda_{\text {ANSYs }}$ & Buckling mode \\
\hline MT1 & 54.9362 & - & LDB \\
\hline MT2 & 20.2109 & 2.72 & LWB at support \\
\hline MT3 & 45.3439 & 1.21 & LDB + LWB at support \\
\hline MT4 & 55.5789 & 0.99 & LDB \\
\hline MT5 & 55.5789 & 0.99 & LDB \\
\hline MT6 & 54.6327 & 1.01 & LDB \\
\hline MT7 & 53.9052 & 1.02 & LDB \\
\hline MT8 & 9.77831 & - & LDB \\
\hline MT9 & 9.79843 & 0.99 & LDB \\
\hline
\end{tabular}

The buckling modes obtained for MT-2 and MT-3 were LWB and an interaction between LWB and LDB, respectively, neither of interest to this study. Comparing models MT-4 and MT- 1 it is possible to conclude that the presence of the web stiffener does not compromise the free warping behavior of the fork support, since the difference between the eigenvalues was of $1 \%$.

With respect to the position of the vertical and longitudinal supports, Table 4 shows that placing the restriction either at the centroid or at the bottom flange (models MT-1 and MT-5) does not significantly alter the results (difference of $1 \%$ between the eigenvalues). Therefore the fact that the cross sections at the supports pivot around either the centroid or the bottom flange does not influence the results and either approach can be adopted.

When comparing models MT-1 with MT-7 and models MT- 8 with MT9 , it is possible to notice that the approach to introduce the bending moment (either the force binary or the elastic triangular force diagram) and its consequent stress distribution did not influence the results, since the $\lambda_{\text {REF }} / \lambda_{\text {ANSYS }}$ ratios were equal to 1.02 and 0.99 , respectively. Based on the observations that resulted from this study of the boundary conditions it is possible to conclude that the boundary conditions of models MT- 5 and MT-10 (displacement restrictions applied at the steel section centroid, LINK180 elements at the supports to prevent distortion, and elastic triangular force diagram to apply the bending moment) are satisfactory for the study of lateral-distortional buckling and were, therefore, adopted in the parametric analysis performed in this paper.

\subsection{Description of the numerical model}

For the validation of the numerical model two kinds of torsional restriction were implemented using the spring element COMBIN14: infinite rotational stiffness (considering that the concrete slab has infinite flexural stiffness) and $k_{1}$ rotational stiffness (calculated based on the actual flexural stiffness of the concrete slab). In each case the elastic critical moment was obtained from the numerical analysis $\left(M_{c r, \infty}\right.$ and $M_{c r}$, respectively). Table 5 displays the examples analyzed in order to validate the numerical model adopted in this paper, with the ratios $\mathrm{k}_{1} / \mathrm{k}_{2}$ and $\mathrm{M}_{\mathrm{cr}} / \mathrm{M}_{\mathrm{cr}, \mathrm{s}}$ taken from 
the graphics presented by Chen and Wang [4]. The slab stiffness $\mathrm{k}_{1}$ was calculated based on the ratios $\mathrm{k}_{1} / \mathrm{k}_{2}$ described by Chen and Wang [4], given that the stiffness of the steel web $\left(k_{2}\right)$ is equal to $70,08 \mathrm{kNm} / \mathrm{m}$, as determined by Equation 8 .

From the graphics in Figure 11 it can be noted that the results of the numerical model present similar behavior to the one obtained by Chen and Wang [4]. The values display a maximum deviation of $4 \%$ for models with $\mathrm{L} / \mathrm{d}$ ratio equal to 8 (Table 5 ) and of $10 \%$ for models with $\mathrm{L} / \mathrm{d}$ ratio equal to 12 (Table 5 ).

Given the results comparison presented it can be concluded that the numerical model adopted in this work is validated and proved itself accurate in the determination of the elastic critical moment associated with lateral-distortional buckling.

\section{Parametric study}

In the parametric study the boundary conditions of the numerical model were altered. The simply supported span (simplified model proposed by Roik, Hanswille and Kina [8]) was simulated, along with models with either two or three spans, representing end and internal composite beam spans. The boundary conditions for a single simply supported span are described in item 2.2. For models with two or three spans the boundary conditions are similar to those of the simply supported beams: all supports restrict vertical displacement and a single support prevents longitudinal displacement.

The steel-concrete composite section represented in Figure 12-a was adopted and the lateral-distortional buckling was studied in this paper using the simplified numerical model of Figure 12-b. To obtain the value of the slab stiffness $\mathrm{k}_{1}$ Equation 7 was applied considering an edge beam (that is, a equals 2 ) and the distance between adjacent parallel beams (a) equal to $200 \mathrm{~cm}$; the flexural stiffness of the homogenized composite section, discarding the concrete under tension, was equal to $528 \mathrm{kNm}$, resulting in $\mathrm{k}_{1}$ equal to $528 \mathrm{kN} / \mathrm{rad}$. The length of the span $(\mathrm{L})$ was equal to $1500 \mathrm{~cm}$, approximately 25 times the depth of the beam. The factor related to the geometry of the cross section of the composite beam $\left(\alpha_{g}\right)$ was

Table 5

Results obtained by Chen and Wang [4] and numerical results obtained in this work

\begin{tabular}{|c|c|c|c|c|}
\hline \multicolumn{5}{|c|}{ a) ratio $\mathbf{L} / \mathbf{d}=\mathbf{8}$} \\
\hline & Chen and Wang (2012) & \multicolumn{2}{c|}{ Numerical results } \\
\hline $\mathbf{k}_{\mathbf{1}} / \mathbf{k}_{\mathbf{2}}$ & $\mathbf{k}_{\mathbf{1}}$ & $\mathbf{M}_{\mathrm{cr}} / \mathbf{M}_{\mathrm{cr}, \infty}$ & $\mathbf{M}_{\mathrm{cr}} / \mathbf{M}_{\mathrm{cr}, \infty}$ & Relative deviation (\%) \\
\hline 0 & 0 & 0.808 & 0.839 & $4 \%$ \\
\hline 0.90 & 62.87 & 0.880 & 0.871 & $-1 \%$ \\
\hline 2.93 & 205.46 & 0.931 & 0.910 & $-2 \%$ \\
\hline 4.97 & 348.25 & 0.949 & 0.931 & $-2 \%$ \\
\hline 6.92 & 484.84 & 0.964 & 0.944 & $-2 \%$ \\
\hline 9.93 & 696.01 & 0.976 & 0.956 & $-2 \%$ \\
\hline 11.97 & 838.91 & 0.976 & 0.962 & $-1 \%$ \\
\hline 14.90 & 1043.92 & 0.979 & 0.983 & $0 \%$ \\
\hline 29.88 & 2093.85 & 0.991 & 0.982 & $-1 \%$ \\
\hline 49.91 & 3497.99 & 0.991 & 0.989 & $0 \%$ \\
\hline
\end{tabular}

\begin{tabular}{|c|c|c|c|c|}
\hline \multicolumn{7}{|c|}{ b) ratio $\mathbf{L} / \mathbf{d}=\mathbf{1 2}$} \\
\hline & Chen and Wang (2012) & \multicolumn{2}{c|}{ Numerical results } \\
\hline $\mathbf{k}_{\mathbf{1}} / \mathbf{k}_{\mathbf{2}}$ & $\mathbf{k}_{1}$ & $\mathbf{M}_{\mathrm{cr}} / \mathbf{M}_{\mathrm{cr}, \infty}$ & $\mathbf{M}_{\mathrm{cr}} / \mathbf{M}_{\mathrm{cr}, \infty}$ & Relative deviation (\%) \\
\hline 0 & 0 & 0.484 & 0.530 & $9 \%$ \\
\hline 1.02 & 75.09 & 0.697 & 0.642 & $-9 \%$ \\
\hline 2.98 & 219.01 & 0.833 & 0.754 & $-10 \%$ \\
\hline 5.02 & 369.19 & 0.885 & 0.814 & $-9 \%$ \\
\hline 6.97 & 513.11 & 0.914 & 0.850 & $-8 \%$ \\
\hline 9.95 & 732.12 & 0.937 & 0.883 & $-6 \%$ \\
\hline 11.99 & 882.29 & 0.946 & 0.899 & $-5 \%$ \\
\hline 14.97 & 1101.30 & 0.955 & 0.915 & $-4 \%$ \\
\hline 29.93 & 2202.61 & 0.979 & 0.954 & $-3 \%$ \\
\hline 49.91 & 3673.10 & 0.986 & 0.971 & $-1 \%$ \\
\hline
\end{tabular}




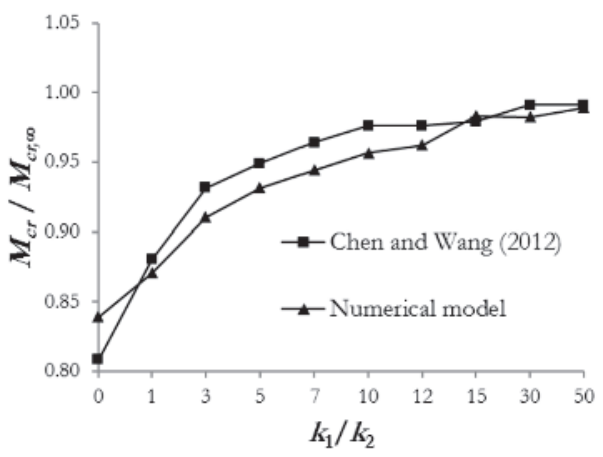

a) ratio $L / d=8$

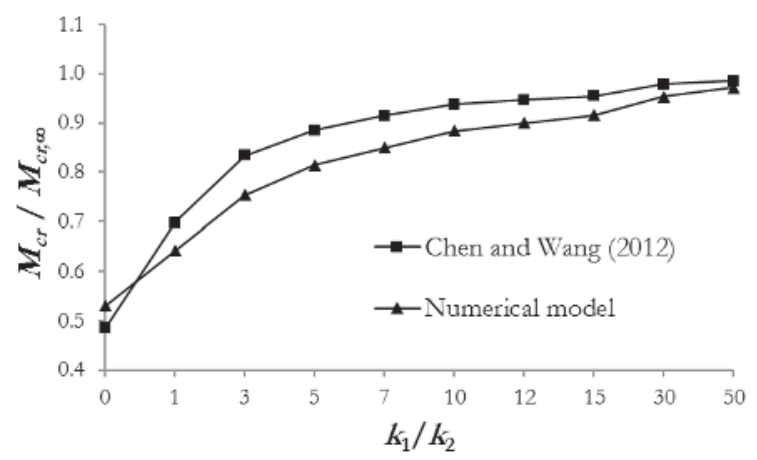

b) ratio $L / d=12$

Figure 11

Comparison between the numerical results obtained in this work and the results published by Chen and Wang [4]

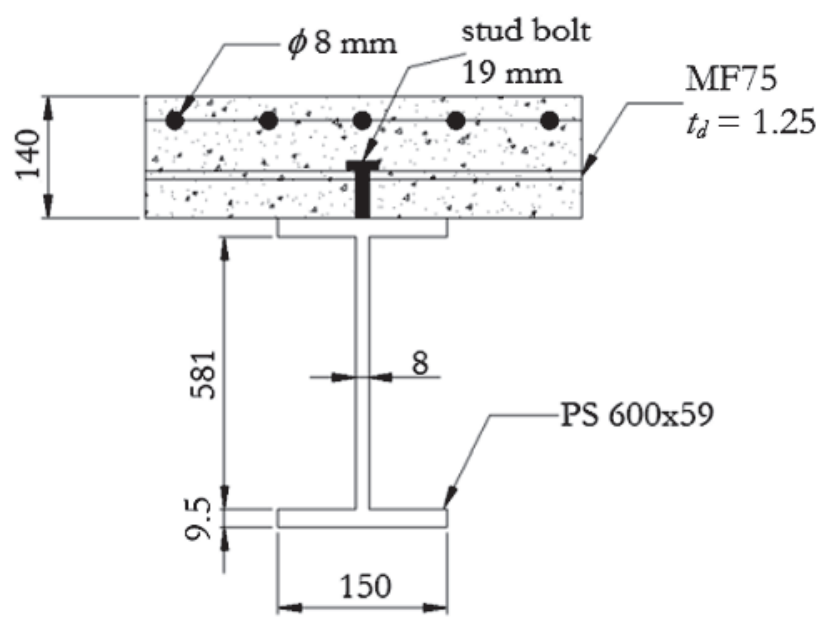

a) Real structure

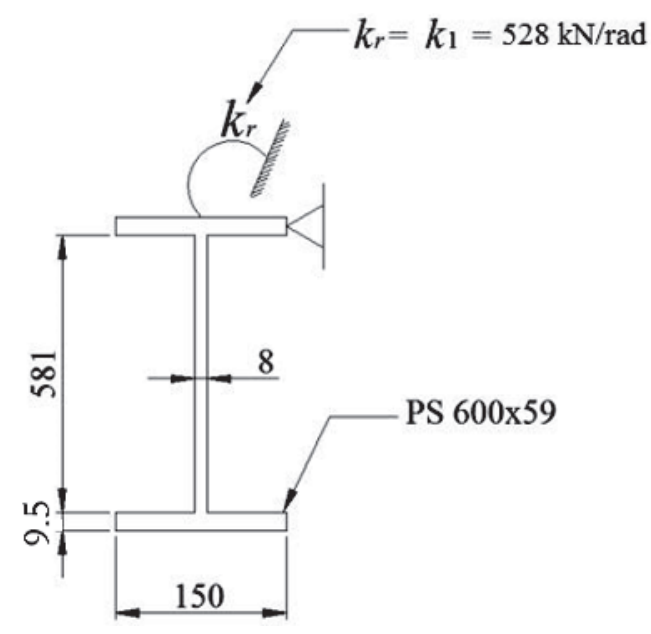

b) Numerical model

\section{Figure 12}

Model adopted for the numerical study

equal to 1.09. Torsional stiffness, $\mathrm{G}_{\mathrm{a}} \mathrm{J}$, was equal to $143617 \mathrm{kNcm}^{2}$ The elastic modulus of the steel was equal to $20000 \mathrm{kN} / \mathrm{cm}^{2}$ and the second moment of area of the bottom flange of the steel section about the $y$ axis $\left(\mathrm{I}_{\text {afy }}\right)$ was equal to $267 \mathrm{~cm}^{4}$. Finally, the ratio $\mathrm{M}_{\mathrm{cr}} / \mathrm{C}_{\text {dist }}$ was equal to $5379 \mathrm{kNcm}$.

All scenarios in Table 1 and Table 2 were studied. The Table 1 beams have either uniformly distributed or point load. $M_{0}$ is the maximum value of the bending moment (at the middle of the span) and though the beams were simply supported, the bending moment at the extremity is equal to $\psi \mathrm{M}_{0}$, a value directly applied to simulate a continuous beam.

For the inner spans of the continuous composite beams with uniformly distributed transverse loads, three possible ratios between the maximum sagging bending moment $\left(M_{0}\right)$ and the hogging bending moment at the extremities were studied: $0.5 \psi \mathrm{M}_{0}$, $0.75 \psi \mathrm{M}_{0}$, and $\psi \mathrm{M}_{0}$.

To simulate the end span of continuous composite beams, simplified models (consisting of a single simply supported span) were adopted and a hogging bending moment $\mathrm{ML}$ was applied at the left end of the beam. The values of ML are listed in Table 6 and Table 8 (models M1 through M9 and M73 through M81). The simplified models of the inner spans were obtained in a similar manner, by applying hogging bending moments $M L$ and $M R$ to the left and right ends (respectively) of a simply supported beam. The values of ML and MR for models M10 through M26 and M82 through M90 are given in Table 6 and Table 8.

To analyze the influence of the adjacent spans a more complex model was adopted. Beams with two spans were modeled to simulate end spans and beams with three spans were modeled to simulate inner spans. For the end spans of continuous beams with uniformly distributed transverse load (models M37 through M45 in Table 7) it was possible to obtain a relation between the distributed loads $q_{1}$ and $q_{2}$ by employing the three-moment equation. Taking the distributed load in the analyzed span $\mathrm{q}_{2}$ as being equal to $1 \mathrm{kN} / \mathrm{m}$ it follows that:

$q_{1}=(2 \psi-1) q_{2}$ 
Similar analytical relations were obtained for the models containing the inner span (M46 through M72 in Table 7) by also applying the three-moment equation to the three possible variations of the bending moment diagram. For the hogging moments at the ends equal to $\psi \mathrm{M}_{0}$ and $0.5 \psi \mathrm{M}_{0}$ the relations are:

$q_{1}=(2,25 \psi-1) q_{2}$

\section{Table 6}

Numerical models of simply supported continuous composite beams with uniformly distributed transverse load

\begin{tabular}{|c|c|c|c|c|c|}
\hline Model & Boundary conditions & $\begin{array}{c}\text { Bending moment } \\
\text { diagram }\end{array}$ & $\psi$ & $M_{L}(k N m)$ & $M_{R}(k N m)$ \\
\hline M1 & \multirow{9}{*}{$\mathrm{N}_{0} 0$} & \multirow{9}{*}{$M_{0} \backslash M_{0} \longrightarrow$} & 0.5 & 14.06 & - \\
\hline M2 & & & 0.75 & 21.09 & - \\
\hline M3 & & & 1 & 28.13 & - \\
\hline M4 & & & 1.25 & 35.16 & - \\
\hline M5 & & & 1.5 & 42.19 & - \\
\hline M6 & & & 1.75 & 49.22 & - \\
\hline M7 & & & 2 & 56.25 & - \\
\hline M8 & & & 2.25 & 63.28 & - \\
\hline M9 & & & 2.5 & 70.31 & - \\
\hline M10 & \multirow{9}{*}{ war } & \multirow{9}{*}{\begin{tabular}{l|l}
$M_{0} M_{0}$ & 0,5 \\
\end{tabular}} & 0.5 & 14.06 & 7.03 \\
\hline M11 & & & 0.75 & 21.09 & 10.55 \\
\hline $\mathrm{M} 12$ & & & 1 & 28.13 & 14.06 \\
\hline M13 & & & 1.25 & 35.16 & 17.58 \\
\hline M14 & & & 1.5 & 42.19 & 21.09 \\
\hline M15 & & & 1.75 & 49.22 & 24.61 \\
\hline M16 & & & 2 & 56.25 & 28.13 \\
\hline M17 & & & 2.25 & 63.28 & 31.64 \\
\hline M18 & & & 2.5 & 70.31 & 35.16 \\
\hline M19 & \multirow{9}{*}{ 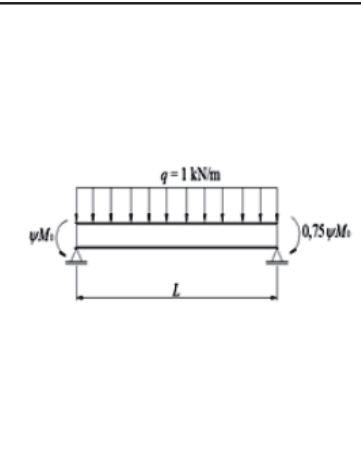 } & \multirow{9}{*}{ 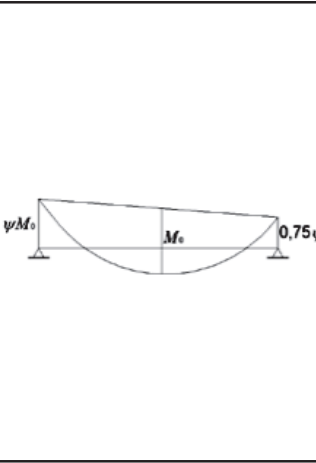 } & 0.5 & 14.06 & 10.55 \\
\hline M20 & & & 0.75 & 21.09 & 15.82 \\
\hline M21 & & & 1 & 28.13 & 21.09 \\
\hline M22 & & & 1.25 & 35.16 & 26.37 \\
\hline M23 & & & 1.5 & 42.19 & 31.64 \\
\hline M24 & & & 1.75 & 49.22 & 36.91 \\
\hline M25 & & & 2 & 56.25 & 42.19 \\
\hline M26 & & & 2.25 & 63.28 & 47.46 \\
\hline M27 & & & 2.5 & 70.31 & 52.73 \\
\hline M28 & \multirow{9}{*}{ 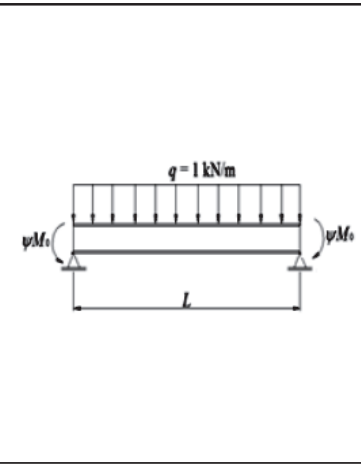 } & \multirow{9}{*}{${ }^{\psi M_{0}}{ }_{\Perp}$} & 0.5 & 14.06 & 14.06 \\
\hline M29 & & & 0.75 & 21.09 & 21.09 \\
\hline M30 & & & 1 & 28.13 & 28.13 \\
\hline M31 & & & 1.25 & 35.16 & 35.16 \\
\hline M32 & & & 1.5 & 42.19 & 42.19 \\
\hline M33 & & & 1.75 & 49.22 & 49.22 \\
\hline M34 & & & 2 & 56.25 & 56.25 \\
\hline M35 & & & 2.25 & 63.28 & 63.28 \\
\hline M36 & & & 2.5 & 70.31 & 70.31 \\
\hline
\end{tabular}


$q_{3}=(1,5 \psi-1) q_{2}$

For bending moments at the end of the analyzed span equal

to $\psi \mathrm{M}_{0}$ and $0.75 \psi \mathrm{M}_{0}$ the relations become:

$q_{1}=(2,375 \psi-1) q_{2}$

\section{Table 7}

Numerical models with two or three spans of continuous composite beams with uniformly distributed transverse load

\begin{tabular}{|c|c|c|c|c|c|}
\hline Model & Boundary conditions & $\begin{array}{c}\text { Bending moment } \\
\text { diagram }\end{array}$ & $\psi$ & $\mathrm{q}_{1}(\mathrm{kN} / \mathrm{m})$ & $\mathrm{q}_{2}(\mathrm{kN} / \mathrm{m})$ \\
\hline M37 & \multirow{9}{*}{ 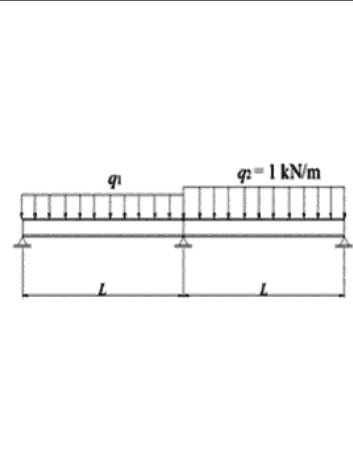 } & \multirow{9}{*}{$\triangle L_{\mu_{0}}$} & 0.5 & 0 & - \\
\hline M38 & & & 0.75 & 0.50 & - \\
\hline M39 & & & 1 & 1.00 & - \\
\hline M40 & & & 1.25 & 1.50 & - \\
\hline M41 & & & 1.5 & 2.00 & - \\
\hline M42 & & & 1.75 & 2.50 & - \\
\hline M43 & & & 2 & 3.00 & - \\
\hline M44 & & & 2.25 & 3.50 & - \\
\hline M45 & & & 2.5 & 4.00 & - \\
\hline M46 & \multirow{9}{*}{ ש. } & \multirow{9}{*}{ 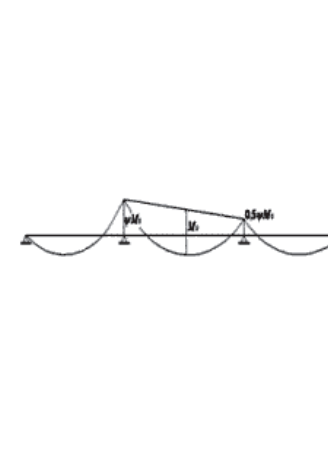 } & 0.5 & 0.13 & -0.25 \\
\hline M47 & & & 0.75 & 0.69 & 0.13 \\
\hline M48 & & & 1 & 1.25 & 0.5 \\
\hline M49 & & & 1.25 & 1.81 & 0.88 \\
\hline M50 & & & 1.5 & 2.38 & 1.25 \\
\hline M51 & & & 1.75 & 2.94 & 1.63 \\
\hline M52 & & & 2 & 3.50 & 2 \\
\hline M53 & & & 2.25 & 4.06 & 2.38 \\
\hline M54 & & & 2.5 & 4.63 & 2.75 \\
\hline M55 & \multirow{9}{*}{ 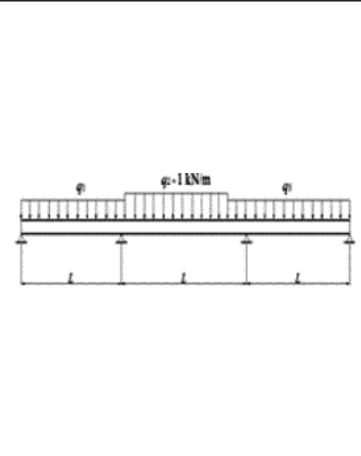 } & \multirow{9}{*}{ 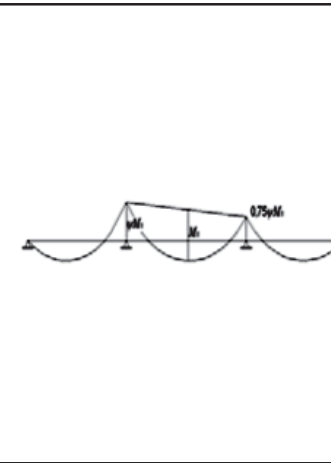 } & 0.5 & 0.19 & 0 \\
\hline M56 & & & 0.75 & 0.78 & 0.5 \\
\hline M57 & & & 1 & 1.38 & 1 \\
\hline M58 & & & 1.25 & 1.97 & 1.5 \\
\hline M59 & & & 1.5 & 2.56 & 2 \\
\hline M60 & & & 1.75 & 3.16 & 2.5 \\
\hline M61 & & & 2 & 3.75 & 3 \\
\hline M62 & & & 2.25 & 4.34 & 3.5 \\
\hline M63 & & & 2.5 & 4.94 & 4 \\
\hline M64 & \multirow{9}{*}{ 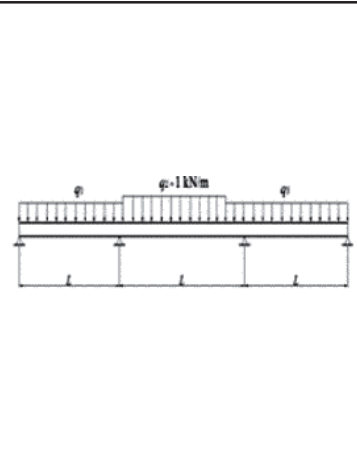 } & \multirow{9}{*}{$\subset{ }^{*}$} & 0.5 & 0.25 & 0.25 \\
\hline M65 & & & 0.75 & 0.88 & 0.88 \\
\hline M66 & & & 1 & 1.50 & 1.5 \\
\hline M67 & & & 1.25 & 2.13 & 2.13 \\
\hline M68 & & & 1.5 & 2.75 & 2.75 \\
\hline M69 & & & 1.75 & 3.38 & 3.38 \\
\hline M70 & & & 2 & 4 & 4 \\
\hline M71 & & & 2.25 & 4.63 & 4.63 \\
\hline M72 & & & 2.5 & 5.25 & 5.25 \\
\hline
\end{tabular}


Table 8

Numerical models of simply supported continuous composite beams with point load

\begin{tabular}{|c|c|c|c|c|c|}
\hline Model & Boundary conditions & $\begin{array}{c}\text { Bending moment } \\
\text { diagram }\end{array}$ & $\psi$ & $M_{L}(k N / m)$ & $M_{R}(k N / m)$ \\
\hline M73 & \multirow{9}{*}{ 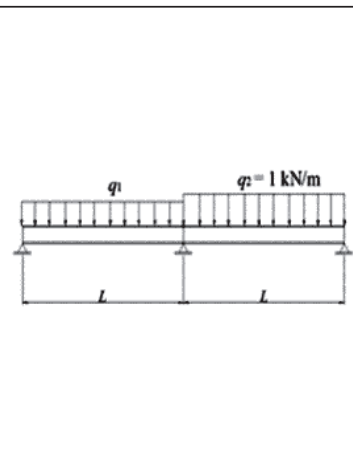 } & \multirow{9}{*}{$\longrightarrow L$} & 0.5 & 1.88 & - \\
\hline M74 & & & 0.75 & 2.81 & - \\
\hline M75 & & & 1 & 3.75 & - \\
\hline M76 & & & 1.25 & 4.69 & - \\
\hline M77 & & & 1.5 & 5.63 & - \\
\hline M78 & & & 1.75 & 6.56 & - \\
\hline M79 & & & 2 & 7.50 & - \\
\hline M80 & & & 2.25 & 8.44 & - \\
\hline M81 & & & 2.5 & 9.38 & - \\
\hline M82 & \multirow{9}{*}{ } & \multirow{9}{*}{ 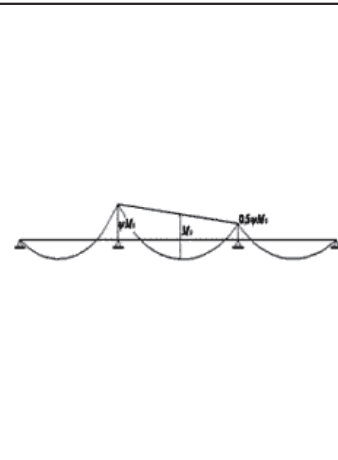 } & 0.5 & 1.88 & 1.88 \\
\hline M83 & & & 0.75 & 2.81 & 2.81 \\
\hline M84 & & & 1 & 3.75 & 3.75 \\
\hline M85 & & & 1.25 & 4.69 & 4.69 \\
\hline M86 & & & 1.5 & 5.63 & 5.63 \\
\hline M87 & & & 1.75 & 6.56 & 6.56 \\
\hline M88 & & & 2 & 7.50 & 7.50 \\
\hline M89 & & & 2.25 & 8.44 & 8.44 \\
\hline M90 & & & 2.5 & 9.38 & 9.38 \\
\hline
\end{tabular}

Table 9

Numerical models of continuous composite beams with two or three spans with point loads

\begin{tabular}{|c|c|c|c|c|c|}
\hline Model & Boundary conditions & $\begin{array}{c}\text { Bending moment } \\
\text { diagram }\end{array}$ & $\psi$ & $P_{1}(k N)$ & $\mathrm{P}_{2}(\mathrm{kN})$ \\
\hline M91 & \multirow[b]{4}{*}{$9 \quad P=$} & \multirow{9}{*}{ 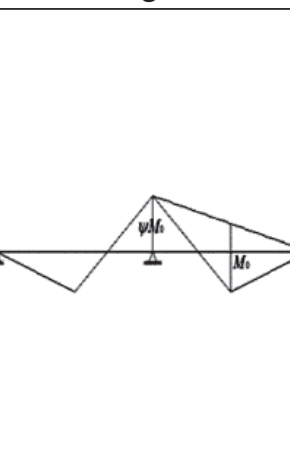 } & 0.5 & 0.33 & - \\
\hline M92 & & & 0.75 & 1 & - \\
\hline M93 & & & 1 & 1.67 & - \\
\hline M94 & & & 1.25 & 2.33 & - \\
\hline M95 & \multirow{5}{*}{ I 1,1,} & & 1.5 & 3 & - \\
\hline M96 & & & 1.75 & 3.67 & - \\
\hline M97 & & & 2 & 4.33 & - \\
\hline M98 & & & 2.25 & 5 & - \\
\hline M99 & & & 2.5 & 5.67 & - \\
\hline M100 & \multirow{9}{*}{ 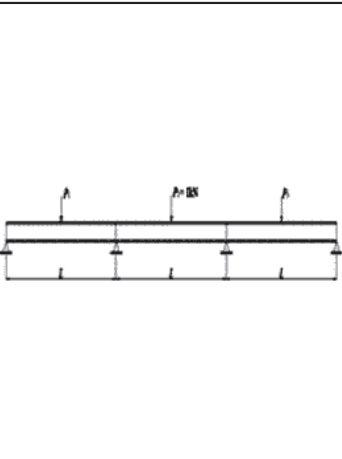 } & \multirow{9}{*}{ 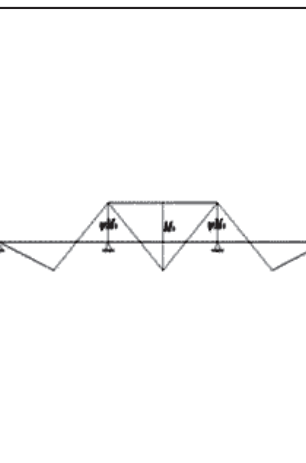 } & 0.5 & 0.67 & 0.67 \\
\hline M101 & & & 0.75 & 1.5 & 1.5 \\
\hline $\mathrm{M} 102$ & & & 1 & 2.33 & 2.33 \\
\hline M103 & & & 1.25 & 3.17 & 3.17 \\
\hline M104 & & & 1.5 & 4 & 4 \\
\hline M105 & & & 1.75 & 4.83 & 4.83 \\
\hline M106 & & & 2 & 5.67 & 5.67 \\
\hline M107 & & & 2.25 & 6.5 & 6.5 \\
\hline M108 & & & 2.5 & 7.33 & 7.33 \\
\hline
\end{tabular}


Table 10

Numerical models of simply supported continuous composite beams without loading along the member length $L$

\begin{tabular}{|c|c|c|c|c|c|}
\hline Model & Boundary conditions & $\begin{array}{c}\text { Bending moment } \\
\text { diagram }\end{array}$ & $\psi$ & $M_{L}(k N / m)$ & $M_{R}(k N / m)$ \\
\hline M109 & \multirow{5}{*}{$\sqrt{[}$} & \multirow{5}{*}{${ }^{M} \beth_{\perp}^{\psi M}$} & 0 & 1 & 0 \\
\hline M110 & & & 0.25 & 1 & 0.25 \\
\hline M111 & & & 0.5 & 1 & 0.5 \\
\hline $\mathrm{M} 112$ & & & 0.75 & 1 & 0.75 \\
\hline M113 & & & 1 & 1 & 1 \\
\hline M114 & \multirow{5}{*}{(} & \multirow{5}{*}{$M \perp \perp^{\psi M}$} & 0 & 1 & 0 \\
\hline M115 & & & 0.25 & 1 & -0.25 \\
\hline M116 & & & 0.5 & 1 & -0.5 \\
\hline M117 & & & 0.75 & 1 & -0.75 \\
\hline M118 & & & 1 & 1 & -1 \\
\hline
\end{tabular}

$q_{3}=(2 \psi-1) q_{2}$

Finally, when the hogging moment at both ends is equal to $\psi \mathrm{M}_{0}$ the relation becomes:

$q_{1}=q_{3}=(2,5 \psi-1) q_{2}$

For continuous composite beams with point loads (models M91 through M99 in Table 9) the three-moment equation was also applied and the relation between the point loads $P_{1}$ and $P_{2}$ is given by Equation 15:

$P_{1}=\left(\frac{8}{3} \psi-1\right) P_{2}$

For the models with the inner span (M100 through M108 in Table 9), the relations between the point loads $P_{1}, P_{2}$ and $P_{3}$ were:

$P_{1}=P_{3}=\left(\frac{10}{3} \psi-1\right) P_{2}$

The beams in Table 2 do not have transverse load applied along the length of the span $(\mathrm{L})$, only hogging moments applied at the ends of the span, which causes the bending moment diagram to display a linear shape. For these cases only the simplified models (a single simply supported span with bending moments applied at the ends) were simulated. For models M109 through M113 in Table 10 a bending moment $M$ of $1 \mathrm{kNm}$ was applied to the left end and a bending moment equal to $\psi \mathrm{M}$ was applied at the right end in order to produce a bending moment diagram with a trapezoidal shape.

\section{Analysis of the results}

\subsection{Numerical models of composite beams with uniformly distributed transverse load}

Table 11 presents the results obtained numerically for the simplified models (M1 through M36) and for the models with more than one span (M37 through M72) with distributed transverse load. The results obtained for the simplified models $\left(M_{c r s}\right)$ and for the models with more than one span $\left(\mathrm{M}_{\mathrm{cr}, \mathrm{v}}\right)$ are confronted with the values obtained by applying Equation 1, proposed by Roik, Hanswille and Kina [8] and adopted by ABNT NBR 8800:2008 ( $\left.\mathrm{M}_{\mathrm{cr}, \mathrm{ABNT}}\right)$.

From Figure 13 it is possible to observe that the simplified model displays the same behavioral tendency that can be generated by applying the formulation prescribed by ABNT NBR 8800:2008, i.e., $M_{c r}$ decreases with the increase of the $\psi$ factor. However, the slope of the curve obtained by implementing the ABNT NBR 8800:2008 procedure is steeper and the numerical results display lower values than the ones obtained from Equation 1.

In Figure 13 it can be noted that beams modeled with more than one span also displayed the same tendency derived from the ABNT NBR 8800:2008 procedure for $\psi$ values greater than 1.0 $\left(M_{c r}\right.$ decreases with the increase of $\left.\psi\right)$. For $\psi$ values below 1.0 it is not possible to analyze the $M_{c r}$ obtained, since in this case the adjacent span is the one that displays the lateral-distortional buckling behavior. It is also clear that the results obtained using the simplified model (single span) are very close to the ones obtained modelling beams with more spans, demonstrating that the adjacent span influences very little in the results collected from the analyzed span. Therefore, it is possible to conclude that the simplified numerical model displays very good accuracy.

When comparing the numerical results of the simplified models with the values obtained by applying the ABNT NBR 8800:2008 procedure (Table 11), ratios of $\mathrm{M}_{\mathrm{cr}, \mathrm{s}} / \mathrm{M}_{\mathrm{cr}, \mathrm{ABNT}}$ ranging from 0.35 to 0.65 for end spans (models M1 through M9) and from 0.43 to 1.11 for inner spans (M10 through M36) were observed. For models with more than one span (M37 through M45) the $M_{c r, v} / M_{c r, A B N T}$ ratio ranges between 0.49 and 0.77 for end spans, meaning that ABNT NBR 8800:2008 predicts unsafe values for the elastic critical moment. For inner spans (models M46 through M72) a greater similarity between numerical values and analytical values was observed, with the $M_{c r, v} / M_{c r, A B N T}$ ratio varying between 0.71 and 1.39 .

\subsection{Numerical models of compositee beams with point load}




\section{Table 11}

Numerical and analytical results of continuous composite beams with uniformly distributed transverse load

\begin{tabular}{|c|c|c|c|c|c|c|c|c|}
\hline \multicolumn{2}{|c|}{ Models } & \multirow[b]{2}{*}{$\psi$} & \multirow[b]{2}{*}{$\mathbf{C}_{\text {dist }}$} & \multirow[b]{2}{*}{$\begin{array}{l}M_{\text {cr.ABNT }} \\
(\mathrm{kNm})\end{array}$} & \multirow[b]{2}{*}{$\begin{array}{c}M_{\mathrm{cr}, \mathrm{s}} \\
(\mathrm{kNm})\end{array}$} & \multirow[b]{2}{*}{$\begin{array}{c}M_{c r, v} \\
(k N m)\end{array}$} & \multirow[b]{2}{*}{$\begin{array}{c}M_{c r, s} / \\
M_{c r, A B N T}\end{array}$} & \multirow[b]{2}{*}{$\begin{array}{c}M_{c r, v} / \\
M_{c r, A B N T}\end{array}$} \\
\hline $\begin{array}{l}\text { Simplified } \\
1 \text { span }\end{array}$ & $\begin{array}{l}\text { With } 2 \text { or } \\
3 \text { spans }\end{array}$ & & & & & & & \\
\hline $\mathrm{M} 1$ & M37 & 0.5 & 41.5 & 2223.26 & 789.20 & 496.71 & 0.35 & 0.22 \\
\hline M2 & M38 & 0.75 & 30.2 & 1617.89 & 715.78 & 642.09 & 0.44 & 0.40 \\
\hline M3 & M39 & 1 & 24.5 & 1312.53 & 659.29 & 649.58 & 0.50 & 0.49 \\
\hline M4 & M40 & 1.25 & 21.1 & 1130.38 & 619.98 & 646.65 & 0.55 & 0.57 \\
\hline M5 & M41 & 1.5 & 19 & 1017.88 & 591.95 & 641.85 & 0.58 & 0.63 \\
\hline M6 & M42 & 1.75 & 17.5 & 937.52 & 571.20 & 637.42 & 0.61 & 0.68 \\
\hline M7 & M43 & 2 & 16.5 & 883.95 & 555.31 & 633.76 & 0.63 & 0.72 \\
\hline M8 & M44 & 2.25 & 15.7 & 841.09 & 542.79 & 630.78 & 0.65 & 0.75 \\
\hline M9 & M45 & 2.5 & 15.2 & 814.30 & 532.69 & 628.36 & 0.65 & 0.77 \\
\hline M10 & M46 & 0.5 & 33.9 & 1816.11 & 777.62 & 526.19 & 0.43 & 0.29 \\
\hline M11 & M47 & 0.75 & 22.7 & 1216.10 & 692.52 & 656.40 & 0.57 & 0.54 \\
\hline $\mathrm{M} 12$ & M48 & 1 & 17.3 & 926.80 & 630.32 & 653.99 & 0.68 & 0.71 \\
\hline M13 & M49 & 1.25 & 14.1 & 755.37 & 587.93 & 643.06 & 0.78 & 0.85 \\
\hline M14 & M50 & 1.5 & 13 & 696.44 & 558.03 & 632.38 & 0.80 & 0.91 \\
\hline M15 & M51 & 1.75 & 12 & 642.87 & 536.02 & 623.62 & 0.83 & 0.97 \\
\hline M16 & M52 & 2 & 11.4 & 610.73 & 519.22 & 616.75 & 0.85 & 1.01 \\
\hline M17 & M53 & 2.25 & 10.9 & 583.94 & 506.00 & 611.40 & 0.87 & 1.05 \\
\hline M18 & M54 & 2.5 & 10.6 & 567.87 & 495.35 & 607.17 & 0.87 & 1.07 \\
\hline M19 & M55 & 0.5 & 28.2 & 1510.75 & 770.93 & 619.86 & 0.51 & 0.41 \\
\hline M20 & M56 & 0.75 & 18 & 964.31 & 679.83 & 661.59 & 0.70 & 0.69 \\
\hline M21 & M57 & 1 & 13.7 & 733.94 & 614.75 & 652.72 & 0.84 & 0.89 \\
\hline M22 & M58 & 1.25 & 11.7 & 626.80 & 570.75 & 637.34 & 0.91 & 1.02 \\
\hline M23 & M59 & 1.5 & 10.6 & 567.87 & 539.77 & 623.43 & 0.95 & 1.10 \\
\hline M24 & M60 & 1.75 & 10 & 535.73 & 516.96 & 612.26 & 0.96 & 1.14 \\
\hline M25 & M61 & 2 & 9.5 & 508.94 & 499.53 & 603.66 & 0.98 & 1.19 \\
\hline M26 & M62 & 2.25 & 9.1 & 487.51 & 485.81 & 597.00 & 1.00 & 1.22 \\
\hline M27 & M63 & 2.5 & 8.9 & 476.80 & 474.75 & 591.75 & 1.00 & 1.24 \\
\hline M28 & M64 & 0.5 & 21.9 & 1173.24 & 760.93 & 631.82 & 0.65 & 0.54 \\
\hline M29 & M65 & 0.75 & 13.9 & 744.66 & 666.41 & 664.87 & 0.89 & 0.89 \\
\hline M30 & M66 & 1 & 11 & 589.30 & 596.53 & 647.70 & 1.01 & 1.10 \\
\hline M31 & M67 & 1.25 & 9.6 & 514.30 & 548.51 & 625.86 & 1.07 & 1.22 \\
\hline M32 & M68 & 1.5 & 8.8 & 471.44 & 514.93 & 607.51 & 1.09 & 1.29 \\
\hline M33 & M69 & 1.75 & 8.3 & 444.65 & 490.43 & 593.63 & 1.10 & 1.34 \\
\hline M34 & M70 & 2 & 8 & 428.58 & 471.84 & 583.22 & 1.10 & 1.36 \\
\hline M35 & M71 & 2.25 & 7.8 & 417.87 & 457.31 & 574.93 & 1.09 & 1.38 \\
\hline M36 & M72 & 2.5 & 7.6 & 407.15 & 445.65 & 567.73 & 1.09 & 1.39 \\
\hline
\end{tabular}




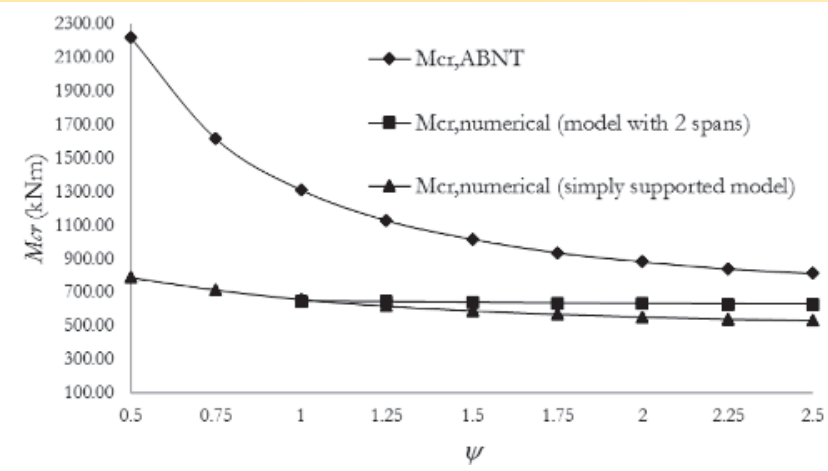

a) end span models (M1 through M9 and M37 through M45)

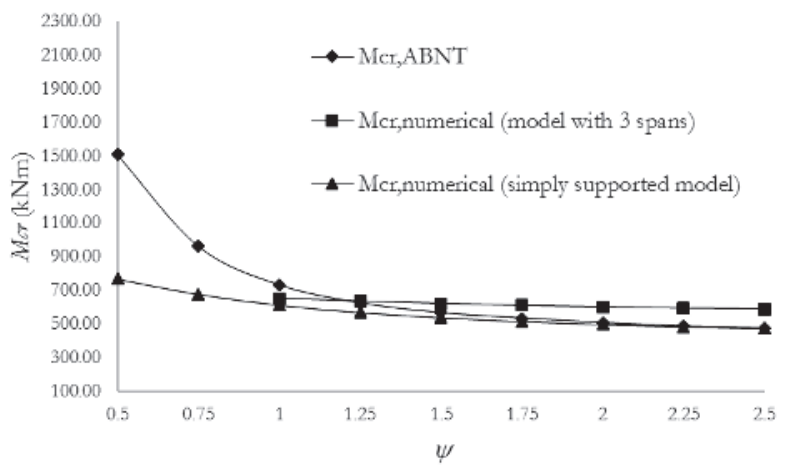

c) inner span models (M19 through M27 and M55 through M63)

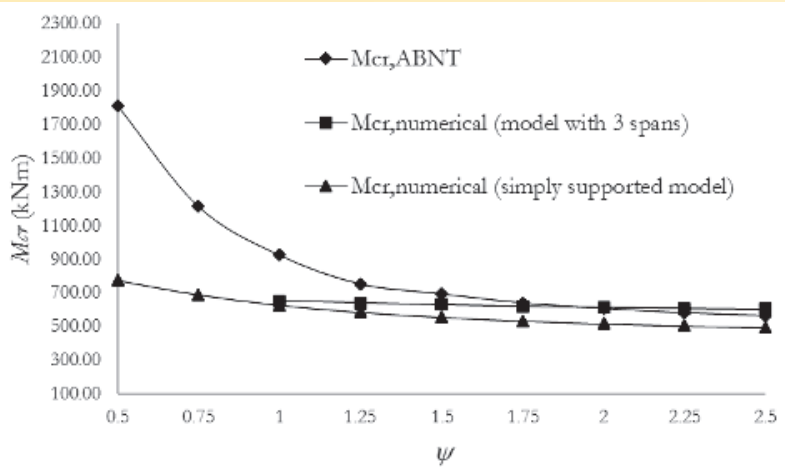

b) inner span models (M10 through M18 and M46 through M54)

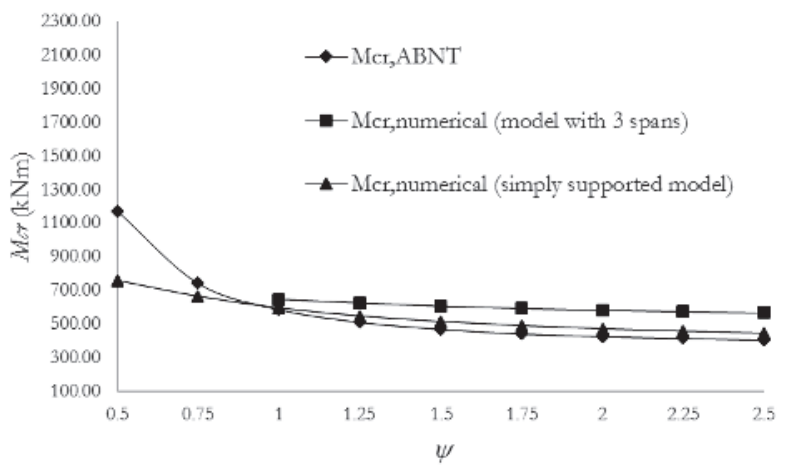

d) inner span models (M28 through M36 and M64 through M72)

Figure 13

$M_{c r} \times \psi$ for continuous composite beams with uniformly distributed load

\section{Table 12}

Numerical and analytical results of continuous composite beams with point loads

\begin{tabular}{|c|c|c|c|c|c|c|c|c|}
\hline \multicolumn{2}{|c|}{ Models } & \multirow[b]{2}{*}{$\psi$} & \multirow[b]{2}{*}{$\mathbf{C}_{\text {dist }}$} & \multirow{2}{*}{$\begin{array}{l}\mathrm{M}_{\mathrm{cr}, \mathrm{ABNT}} \\
(\mathrm{kNm})\end{array}$} & \multirow{2}{*}{$\begin{array}{c}\mathrm{M}_{\mathrm{cr,s}} \\
(\mathrm{kNm})\end{array}$} & \multirow{2}{*}{$\underset{(k N m)}{M_{c r, v}}$} & \multirow[b]{2}{*}{$\begin{array}{c}M_{c r, s} / \\
M_{c r, A B N T}\end{array}$} & \multirow[b]{2}{*}{$\begin{array}{c}M_{\mathrm{cr}, \mathrm{v}} / \\
M_{\mathrm{cr}, \mathrm{ABNT}}\end{array}$} \\
\hline $\begin{array}{c}\text { Simplified } \\
1 \text { span }\end{array}$ & $\begin{array}{l}\text { With } 2 \text { or } \\
3 \text { spans }\end{array}$ & & & & & & & \\
\hline M73 & M91 & 0.5 & 28.4 & 1521.46 & 687.29 & 582.41 & 0.45 & 0.38 \\
\hline M74 & M92 & 0.75 & 21.8 & 1167.88 & 617.80 & 609.90 & 0.53 & 0.52 \\
\hline M75 & M93 & 1 & 18.6 & 996.45 & 577.94 & 602.99 & 0.58 & 0.61 \\
\hline M76 & M94 & 1.25 & 16.7 & 894.66 & 552.58 & 592.30 & 0.62 & 0.66 \\
\hline M77 & M95 & 1.5 & 15.6 & 835.73 & 535.10 & 582.52 & 0.64 & 0.70 \\
\hline M78 & M96 & 1.75 & 14.8 & 792.87 & 522.33 & 622.65 & 0.66 & 0.79 \\
\hline M79 & M97 & 2 & 14.2 & 760.73 & 512.60 & 567.22 & 0.67 & 0.75 \\
\hline M80 & M98 & 2.25 & 13.8 & 739.30 & 504.93 & 561.33 & 0.68 & 0.76 \\
\hline M81 & M99 & 2.5 & 13.5 & 723.23 & 498.74 & 556.33 & 0.69 & 0.77 \\
\hline M82 & M100 & 0.5 & 12.7 & 680.37 & 636.42 & 617.16 & 0.94 & 0.91 \\
\hline M83 & M101 & 0.75 & 9.89 & 529.83 & 554.48 & 595.37 & 1.05 & 1.12 \\
\hline M84 & M102 & 1 & 8.6 & 460.72 & 507.39 & 563.68 & 1.10 & 1.22 \\
\hline M85 & M103 & 1.25 & 8 & 428.58 & 477.59 & 537.51 & 1.11 & 1.25 \\
\hline M86 & M104 & 1.5 & 7.7 & 412.51 & 457.03 & 516.42 & 1.11 & 1.25 \\
\hline M87 & M105 & 1.75 & 7.4 & 396.44 & 441.96 & 499.16 & 1.11 & 1.26 \\
\hline M88 & M106 & 2 & 7.2 & 385.72 & 430.42 & 484.87 & 1.12 & 1.26 \\
\hline M89 & M107 & 2.25 & 7.1 & 380.36 & 421.29 & 472.93 & 1.11 & 1.24 \\
\hline M90 & M108 & 2.5 & 7 & 375.01 & 413.88 & 462.90 & 1.10 & 1.23 \\
\hline
\end{tabular}




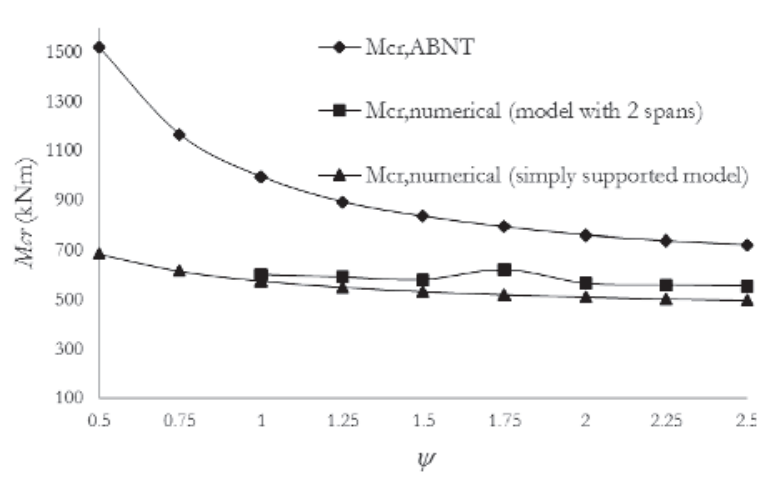

a) end span models (M73 through M81 and M91 through M99)

\section{Figure 14}

$M_{c r} \times \psi$ for continuous composite beams with point loads

Table 12 displays the results obtained numerically for the simplified models (M73 through M90) and for the models with more than one span (M91 through M108) with point loads. The results obtained for the simplified models $\left(\mathrm{M}_{\mathrm{crs}}\right)$ and for the models with more than one span $\left(\mathrm{M}_{\mathrm{cr}, \mathrm{v}}\right)$ were confronted against those obtained by applying Equation $1\left(\mathrm{M}_{\mathrm{cr}, \mathrm{ABNT}}\right)$.

From Figure 14-a it is possible to observe that the numerical models, both the simplified and those with more than a single span, displayed the same overall behavior detected in the models with distributed load (Figure 13-a). Figure 14-b shows that for all values of $\psi$ the numerical results are higher than those obtained by applying the ABNT NBR 8800:2008 procedure.

When comparing the numerical results of the simplified models against the ABNT NBR 8800:2008 results (Table 12), ratios of $M_{c r s} /$ $M_{\text {cr,ABNT }}$ ranging from 0.45 to 0.69 for end spans (M73 through M81) and from 0.94 to 1.11 for inner spans (M82 through M90) were observed. For models with more than one span (M91 through M99) the $M_{c r, v} / M_{c r, A B N T}$ ratio ranges between 0.38 and 0.79 for end spans,

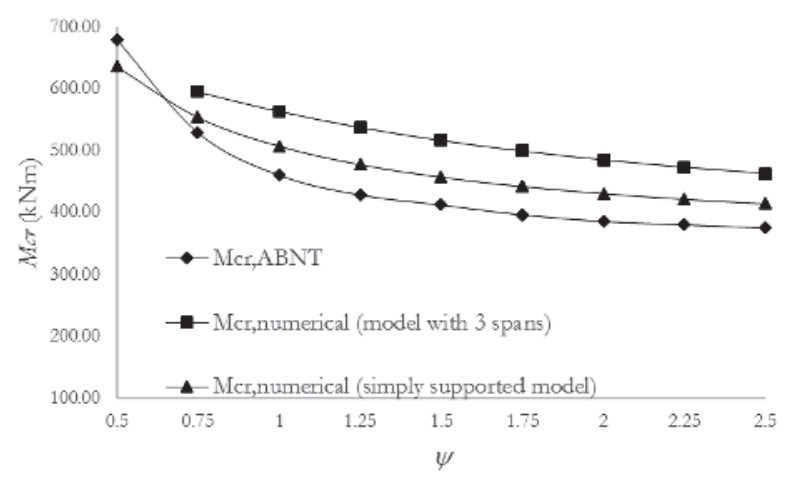

b) inner span models (M82 through M90 and M100 through M108)

\section{Table 13}

Numerical and analytical results of continuous composite beams without loading along the member length L

\begin{tabular}{|c|c|c|c|c|c|}
\hline Models & \multirow{2}{*}{$\psi$} & \multirow{2}{*}{$\mathrm{C}_{\text {dist }}$} & \multirow{2}{*}{$\begin{array}{l}M_{\text {cr,ABNT }} \\
(\mathrm{kNm})\end{array}$} & \multirow{2}{*}{$\begin{array}{c}\mathrm{M}_{\mathrm{cr,b}} \\
(\mathrm{kNm})\end{array}$} & \multirow{2}{*}{$M_{c r, b} / M_{c r, A B N T}$} \\
\hline Simply supported & & & & & \\
\hline M109 & 0 & 11.1 & 594.66 & 440.29 & 0.74 \\
\hline M110 & 0.25 & 9.5 & 508.94 & 420.20 & 0.83 \\
\hline M111 & 0.5 & 8.2 & 439.29 & 398.70 & 0.91 \\
\hline M112 & 0.75 & 7.1 & 380.36 & 375.05 & 0.99 \\
\hline M113 & 1 & 6.2 & 332.15 & 344.77 & 1.04 \\
\hline M114 & 0 & 11.1 & 594.66 & 440.29 & 0.74 \\
\hline M115 & 0.25 & 12.8 & 685.73 & 459.41 & 0.67 \\
\hline M116 & 0.5 & 14.6 & 782.16 & 477.81 & 0.61 \\
\hline M117 & 0.75 & 16.3 & 873.23 & 495.66 & 0.57 \\
\hline M1 18 & 1 & 18.1 & 969.66 & 513.03 & 0.53 \\
\hline
\end{tabular}

meaning that yet again ABNT NBR8800:2008 predicts unsafe values for the elastic critical moment $M_{c r}$. For inner spans (models M100 through M108) a greater similarity between numerical values and analytical values was observed, with the $M_{c r, v} M_{c r, A B N T}$ ratio varying between 1.12 and 1.26, always predicting safe values.

\subsection{Numerical models of composite beams without transverse loads}

Table 13 presents the results obtained numerically for the simplified models with hogging moments at the ends causing a single curvature (M109 through M113) and for the models with bending moments at the ends generating a double curvature (M91 through M108). The results obtained using the simply supported model $\left(M_{c r, b}\right)$ were confronted with the ones obtained by applying the procedure prescribed by ABNT NBR 8800:2008 ( $\left.\mathrm{M}_{\mathrm{cr}, \mathrm{ABNT}}\right)$.

From Figure 15 it can be noted that the simply supported model displays the same behavioral tendency than can be generated 


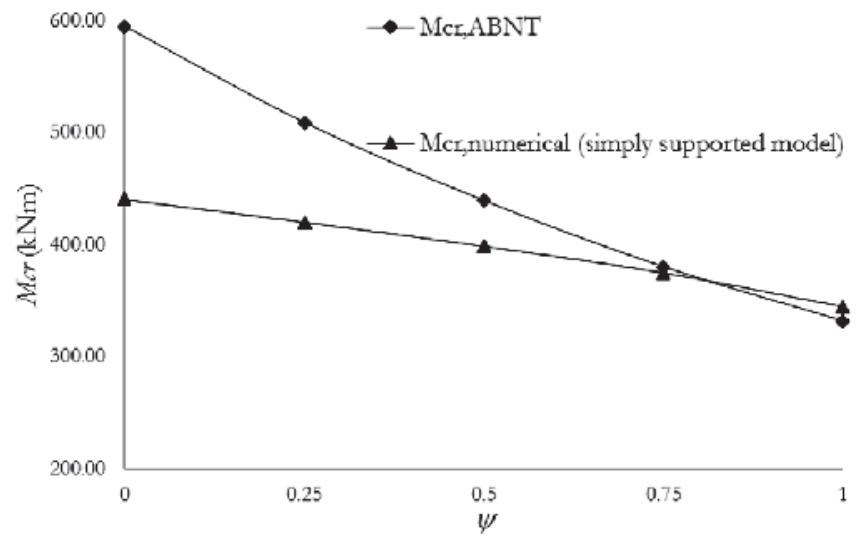

a) models with single curvature (M109 through M113)

\section{Figure 15}

$M_{c r} \times \psi$ for continuous composite beams without loads along member length $L$

by applying the ABNT NBR8800:2008 method, i.e., $M_{c}$ decreases with the increase of the $\psi$ factor. However, the slope of the curves associated with $\mathrm{M}_{\mathrm{cr}, \mathrm{ABNT}}$ is steeper than the one associated with the numerical results. The numerical model returns values that are inferior to those obtained by applying Equation 1 in all cases but the one in which there is single curvature and $\psi$ is greater than 0.5 . From Table 13 the $M_{\text {cr,s }} / M_{\text {cr,ABNT }}$ ratio can be seen ranging from 0.74 to 1.04 (models M109 through M113, single curvature) and from 0.53 to 0.74 (models M114 through M118, double curvature), leading to the conclusion that ABNT NBR 8800:2008 predicts unsafe values for $M_{c r}$ (except for beams with a single curvature when $\psi$ is greater than 0.5 ).

\subsection{Proposed values for the modification parameter}

Previous discussion in items 4.1 through 4.3 showed there was Equation 17.

$C_{\text {distnum }}=\frac{M_{c r, \text { num }}}{\frac{\alpha_{g}}{L} \sqrt{\left(G_{a} J+k_{r} \frac{L^{2}}{\pi^{2}}\right) E_{a} I_{\text {afy }}}}$

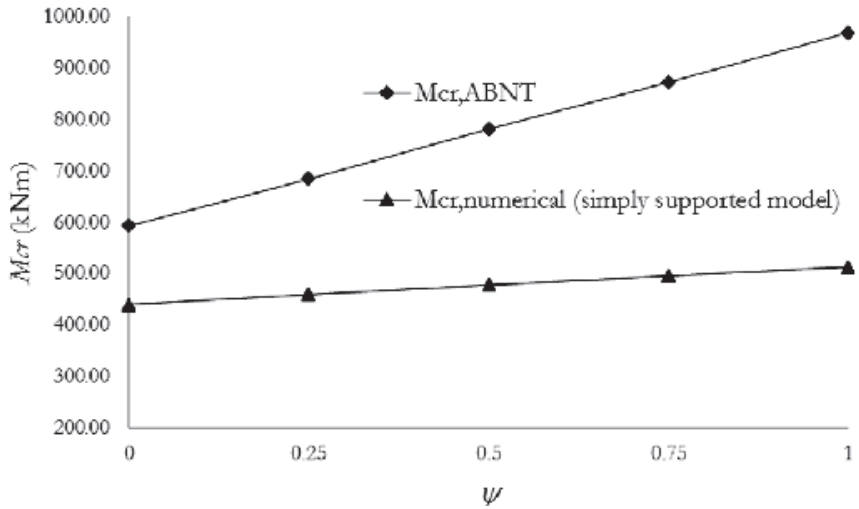

b) models with double curvature (M114 through M118)

a small difference between the simplified models and the models with more than one span. Since models with multiple spans more accurately simulate the behavior of continuous composite beams, the use of Table 14 and Table 15 is suggested in place of Table 1 and Table 2 from ABNT NBR 8800:2008 in order to determine the values of the $C_{\text {dist }}$ coefficient. The $C_{\text {dist }}$ values in Table 14 and Table 15 were obtained based on the numerical results by applying

in which $M_{o r}$ is the value of the elastic critical moment obtained using the numerical models with more than one span, if $\psi$ is equal to or greater than 1 , and using the numerical models with a single

\section{Table 14}

Proposed values of $\mathrm{C}_{\text {dist }}$ for spans with uniformly distributed or point loads

\begin{tabular}{|c|c|c|c|c|c|c|c|c|c|c|}
\hline \multirow{2}{*}{$\begin{array}{l}\text { Loading } \\
\text { and } \\
\text { boundary } \\
\text { conditions }\end{array}$} & \multirow{2}{*}{$\begin{array}{l}\text { Bending } \\
\text { moment } \\
\text { diagram' }\end{array}$} & \multicolumn{9}{|c|}{$C_{\text {dist }}$} \\
\hline & & $\psi=0.50$ & $\psi=0.75$ & $\psi=1.00$ & $\psi=1.25$ & $\psi=1.50$ & $\psi=1.75$ & $\psi=2.00$ & $\psi=2.25$ & $\psi=2.50$ \\
\hline \multirow{2}{*}{ 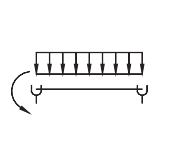 } & ${ }^{\mu \mathrm{M}_{0}} \longrightarrow \prod_{1}^{\mathrm{M}_{0}}$ & 14.7 & 13.4 & 12.1 & 12.1 & 12.0 & 11.9 & 11.8 & 11.8 & 11.7 \\
\hline & 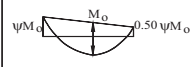 & 14.5 & 12.9 & 12.2 & 12.0 & 11.8 & 11.6 & 11.5 & 11.4 & 11.3 \\
\hline \multirow{2}{*}{ 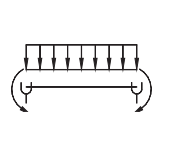 } & 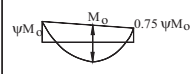 & 14.4 & 12.7 & 12.2 & 11.9 & 11.6 & 11.4 & 11.3 & 11.1 & 11.0 \\
\hline & ${ }^{\psi M_{0}} \bigcirc-{ }^{M_{0}}$ & 14.2 & 12.4 & 12.1 & 11.7 & 11.3 & 11.1 & 10.9 & 10.7 & 10.6 \\
\hline$\left(\begin{array}{l}1 \\
\psi\end{array}\right.$ & ${ }^{\mu \mathrm{M}_{0}} \square \sum^{\mathrm{M}_{\mathrm{o}}}$ & 12.8 & 11.5 & 11.3 & 11.1 & 10.9 & 11.6 & 10.6 & 10.5 & 10.4 \\
\hline$\left(\begin{array}{l}1 \\
(Y+4)\end{array}\right.$ & $\psi M_{0} \triangle \sum^{M_{0}}{ }^{\mu M_{0}}$ & 11.9 & 11.1 & 10.5 & 10.0 & 9.6 & 9.3 & 9.1 & 8.8 & 8.6 \\
\hline
\end{tabular}

Note: ${ }^{1} M_{0}$ is the maximum design value of the bending moment, considering the analyzed span as simply supported. 
Table 15

Proposed values of $C_{\text {dist }}$ for spans without loads along the member length $L$

\begin{tabular}{|c|c|c|c|c|c|c|}
\hline \multirow{2}{*}{$\begin{array}{l}\text { Loading and } \\
\text { boundary } \\
\text { conditions }\end{array}$} & \multirow{2}{*}{$\begin{array}{l}\text { Bending moment } \\
\text { diagram }{ }^{1}\end{array}$} & \multicolumn{5}{|c|}{$\mathbf{C}_{\text {dist }}$} \\
\hline & & $\psi=0.00$ & $\psi=0.25$ & $\psi=0.50$ & $\psi=0.75$ & $\psi=1.00$ \\
\hline$\left(\begin{array}{ll}Y & \psi\end{array}\right)$ & $\mathrm{M} \square_{\text {acceptable }} \cup \mathrm{M}$ & 8.2 & 7.8 & 7.4 & 7.0 & 6.4 \\
\hline$\left(\begin{array}{ll}4 & 4\end{array}\right)$ & ${ }_{\text {acceptable }} \longrightarrow \mathrm{M}$ & 8.2 & 8.6 & 8.9 & 9.3 & 9.6 \\
\hline
\end{tabular}

Note: ' $\mathrm{M}$ is the maximum design hogging moment, in absolute value, at the analyzed span, considering that $\psi$ values grater than 1.00 have to be taken as 1.00 .

simply supported span if $\psi$ is smaller than 1.

\section{Conclusion}

In this paper, numerical models were developed in the finite element software Ansys to simulate the lateral-distortional buckling behavior of continuous steel-concrete composite beams and determine the elastic critical moment. The different boundary conditions presented in ABNT NBR 8800:2008 were replicated in simplified models with a single simply supported span and in more complex models with more than one span, which made it possible to evaluate the modification parameter $\mathrm{C}_{\text {dist. }}$. The influence of the bending moment distribution was analyzed and ultimately led to the conclusion that the formulation proposed by ABNT NBR 8800:2008 might lead to unsafe predictions.

This paper proposes new values for the modification parameter $\mathrm{C}_{\text {dist }}$ based on the numerical results obtained for models with more than a single span and a $\psi$ value greater than 1 . Since in models with more than one span it is not possible to analyze the cases in which $\psi$ is smaller than 1 , the $C_{\text {dist }}$ obtained in the simplified numerical model (single simply supported span) was used. The observation was made that, for continuous composite beams, the bending moment distribution along the length of the span influences very little the resulting $M_{c r}$ value, given that the $C_{\text {dist }}$ values are nearly constant. A revision of the $C_{\text {dist }}$ values proposed by ABNT NBR 8800:2008 is recommended based on the $C_{\text {dist }}$ values obtained numerically in this paper.

\section{Acknowledgments}

The authors acknowledge the support provided by the Brazilian public agencies CNPq, CAPES, FAPES and FAPEMIG in the development of this research.

\section{References}

[1] Ansys, INC., 2011. Release 15.0 Documentation for ANSYS. Canonsburg: [s.n.].

[2] Associação Brasileira de Normas Técnicas - ABNT. ABNT NBR 8800:2008Projeto de estrutura de aço e de estrutura mista de aço e concreto de edifícios. Rio de Janeiro.

[3] Calenzani, A.F.G., Fakury, R.H., Paula, F.A., Rodrigues, F.C.,
Queiroz, G. \& Pimenta, R.J., 2012. Rotational stiffness of continuous composite beams with sinusoidal-web profiles for torsional buckling.Journal of Constructional Steel Research, n.79, p. 22-33.

[4] CEN, EN 1994-1-1:2004. Eurocode4:Design of composite steel and concrete structures - Part 1-1: general rules and rules for buildings. Bruxelas, Bélgica.

[5] Chen, S. \& Wang, X., 2012.Finite Element Analysis of Distortional Lateral Buckling of Continuous Composite Beams with Transverse Web Stiffeners.Advances in Structural Engineering, vol. 15, pp. 1607-1616.

[6] Ng, M.L.H. \&Ronagh, H.R., 2004. An analytical solution for the elastic lateral-distortional buckling of I-section beams. Advances in Structural Engineering, vol. 7, p. 189-200.

[7] Oliveira, J.P.S., 2014. Determinação do momento crítico de flambagem lateral com distorção em vigas mistas contínuas de aço e concreto com perfis de alma senoidal. Dissertação, Universidade Federal do Espírito Santo, Vitória.

[8] Roik, K., Hanswille, G. \& Kina, J., 1990.Solution for the lateral torsional buckling problem of composite beams. Stahlbau, n-59, 327 - 332 (em alemão). 